\title{
Systematic Review of Important Bacterial Zoonoses in Africa in the Last Decade in Light of the 'One Health' Concept
}

\author{
Jonathan Asante ${ }^{1}$, Ayman Noreddin ${ }^{2}$ and Mohamed E. El Zowalaty ${ }^{2, *(\mathbb{D}}$ \\ 1 Virology and Microbiology Research Group, School of Health Sciences, College of health Sciences, \\ University of KwaZulu-Natal, Westville Campus, Durban 4000, South Africa; josante33@yahoo.com \\ 2 Infectious Diseases and Anti-Infective Therapy Research Group, Sharjah Medical Research Institute and \\ College of Pharmacy, University of Sharjah, Sharjah 27272, United Arab Emirates; anoreddin@sharjah.ac.ae \\ * Correspondence: elzow001@gmail.com or elzow005@gmail.com; Tel.: +971-(56)-307-9774
}

Received: 23 March 2019; Accepted: 11 April 2019; Published: 16 April 2019

\begin{abstract}
Zoonoses present a major public health threat and are estimated to account for a substantial part of the infectious disease burden in low-income countries. The severity of zoonotic diseases is compounded by factors such as poverty, living in close contact with livestock and wildlife, immunosuppression as well as coinfection with other diseases. The interconnections between humans, animals and the environment are essential to understand the spread and subsequent containment of zoonoses. We searched three scientific databases for articles relevant to the epidemiology of bacterial zoonoses/zoonotic bacterial pathogens, including disease prevalence and control measures in humans and multiple animal species, in various African countries within the period from 2008 to 2018. The review identified 1966 articles, of which 58 studies in 29 countries met the quality criteria for data extraction. The prevalence of brucellosis, leptospirosis, Q fever ranged from $0-40 \%, 1.1-24 \%$ and 0.9-28.2\%, respectively, depending on geographical location and even higher in suspected outbreak cases. Risk factors for human zoonotic infection included exposure to livestock and animal slaughters. Dietary factors linked with seropositivity were found to include consumption of raw milk and locally fermented milk products. It was found that zoonoses such as leptospirosis, brucellosis, $Q$ fever and rickettsiosis among others are frequently under/misdiagnosed in febrile patients seeking treatment at healthcare centres, leading to overdiagnoses of more familiar febrile conditions such as malaria and typhoid fever. The interactions at the human-animal interface contribute substantially to zoonotic infections. Seroprevalence of the various zoonoses varies by geographic location and species. There is a need to build laboratory capacity and effective surveillance processes for timely and effective detection and control of zoonoses in Africa. A multifaceted 'One Health' approach to tackle zoonoses is critical in the fight against zoonotic diseases. The impacts of zoonoses include: (1) Humans are always in contact with animals including livestock and zoonoses are causing serious life-threatening infections in humans. Almost $75 \%$ of the recent major global disease outbreaks have a zoonotic origin. (2) Zoonoses are a global health challenge represented either by well-known or newly emerging zoonotic diseases. (3) Zoonoses are caused by all-known cellular (bacteria, fungi and parasites) and noncellular (viruses or prions) pathogens. (4) There are limited data on zoonotic diseases from Africa. The fact that human health and animal health are inextricably linked, global coordinated and well-established interdisciplinary research efforts are essential to successfully fight and reduce the health burden due to zoonoses. This critically requires integrated data from both humans and animals on zoonotic diseases.
\end{abstract}

Keywords: Zoonosis; livestock; bacteria; antimicrobial resistance; animals; Africa; antibiotics; One-health; epidemiology 


\section{Introduction}

Zoonoses are infectious diseases caused by pathogens through the natural transmission between animals and man, directly (through agents such as saliva, blood, mucous and faeces) or indirectly (i.e., through environmental sources and vectors) [1]. Of all known human pathogens, including viruses, bacteria, fungi and parasites, an estimated $61 \%$ are regarded as zoonotic, with approximately $73 \%$ of emerging and re-emerging infections being considered as zoonoses [2]. Globally, it is estimated that 2.5 billion cases related to zoonotic infections are recorded yearly, resulting in 2.7 million deaths [3]. Zoonotic diseases account for $25 \%$ of the infectious disease burden in low-income countries, as poverty increases the risk for zoonotic diseases in communities where people are in close contact with livestock and wildlife [4,5]. The World Health Organization (WHO) estimated that, in 2010, there were 600 million cases of foodborne diseases, 350 million of which were caused by pathogenic bacteria [6]. A combined disease burden is imposed on people in poor areas such as tropical and subtropical Africa, where there is the likelihood of zoonotic diseases coinfection with other pathogenic or infectious diseases, such as malaria, tuberculosis and HIV. These associated factors may increase the severity of diseases and the susceptibility of individuals to infectious zoonotic agents, thus enhancing their spread at the community level [7]. Examples of bacterial zoonoses include anthrax, botulism, plague and tularemia, which are listed in category A warfare agents [8,9]. Bacterial zoonoses listed in category B agents include brucellosis, foodborne agents (E. coli O157:H7, salmonellosis and shigellosis), glanders, psittacosis, melioidosis, Q-fever, and typhus fever [9]. Zoonotic pathogens such as Campylobacter, Salmonella, Listeria monocytogenes and the Enterobacteriaceae family are frequently found in livestock (avian, bovine, caprine, equine, ovine and porcine) as well as in wild animals, pets and rodents, causing foodborne diseases. In immunocompromised populations, such as those with a high prevalence of HIV infection, the occurrence of zoonotic diseases is even higher. HIV infection, by depressing the immune systems leads to increased severity of symptoms of many zoonotic diseases and prolonged illness [1].

The absence of effective human monitoring and surveillance programs for zoonotic diseases coupled with limited laboratory capacities leads to a lack of clinical alertness, resulting in underdiagnoses and the subsequent mismanagement of these diseases. This further presents a challenge in detecting new and re-emerging pathogens early $[10,11]$. Zoonotic pathogens that tend to cause epidemics are usually given more attention regarding characterisation and policy-making than those that do not, despite the latter group having a major impact on rural communities [8].

The public health burden and socioeconomic effects of zoonotic diseases may vary according to geographical location, with a lack of data on disease burden in developing countries resulting in an underestimation of their impact [8].

Antimicrobial resistance has become a subject of global interest; especially as the use of antimicrobial agents continue to rise in both clinical and veterinary practices [12]. Microorganisms adapt to the effects of antimicrobial agents through numerous mechanisms, to enable them to survive in the presence of therapeutic concentrations of the antimicrobials. Thus, infections caused by pathogenic bacteria have become increasingly difficult to treat, due to the various antibiotic resistance mechanisms deployed by bacteria to evade the effects of antibiotics [12,13].

Humans, animals and the environment are interconnected in a complex and diversified manner. The interaction between humans, animals and the environment means that infections/resistance that originate in humans, animals, foods and farms will predictably lead to the spread of infection/resistant bacteria and/or resistance genes in the environment $[13,14]$. This dissemination of resistance may be facilitated by excreta coming into contact with soils as well as surface and ground water [14]. Thus, the 'One Health' approach seeks to amalgamate human and veterinary medicine, environmental sciences and public health to develop effective surveillance techniques, accompanied by appropriate diagnostic and therapeutic interventions. This holistic and coordinated approach will lead to the enactment of more thorough and effective policies [15].

This is the first timely, comprehensive, and updated systematic review about the significant bacterial zoonotic diseases in Africa over the past decade. The review summarises relevant publications 
reporting on occurrence, diagnosis and control of bacterial zoonoses in Africa within the last decade. The special focus of this study on Africa is explained by the limited data on disease burden of bacterial zoonoses within the continent, as well as the lack of effective monitoring and surveillance policies/techniques. The majority of African countries are classified as low- and middle-income nations; hence, the risk of disease transmission in communities in close contact with livestock is compounded by poverty. Furthermore, several countries in Africa specifically western and eastern Africa are at high risks of zoonotic diseases, where there are areas characterized by interplay of intense livestock animals, agricultural activities, and poor health services [16]. Furthermore, the risk of disease transmission in communities in close contact with livestock is compounded by poverty. Thus, the review provides important information to fill in the information gap.

\section{Methods}

\subsection{Systematic Review Protocol}

The systematic review followed the standard systematic review procedures established by the Preferred Reporting Items for Systematic Reviews and Meta-Analyses (PRISMA). The review used the following guidelines: (a) a database search to identify potentially relevant articles, (b) evaluating the relevance of articles, (c) quality assessment and (d) extraction of data, and are summarised in Figure 1.

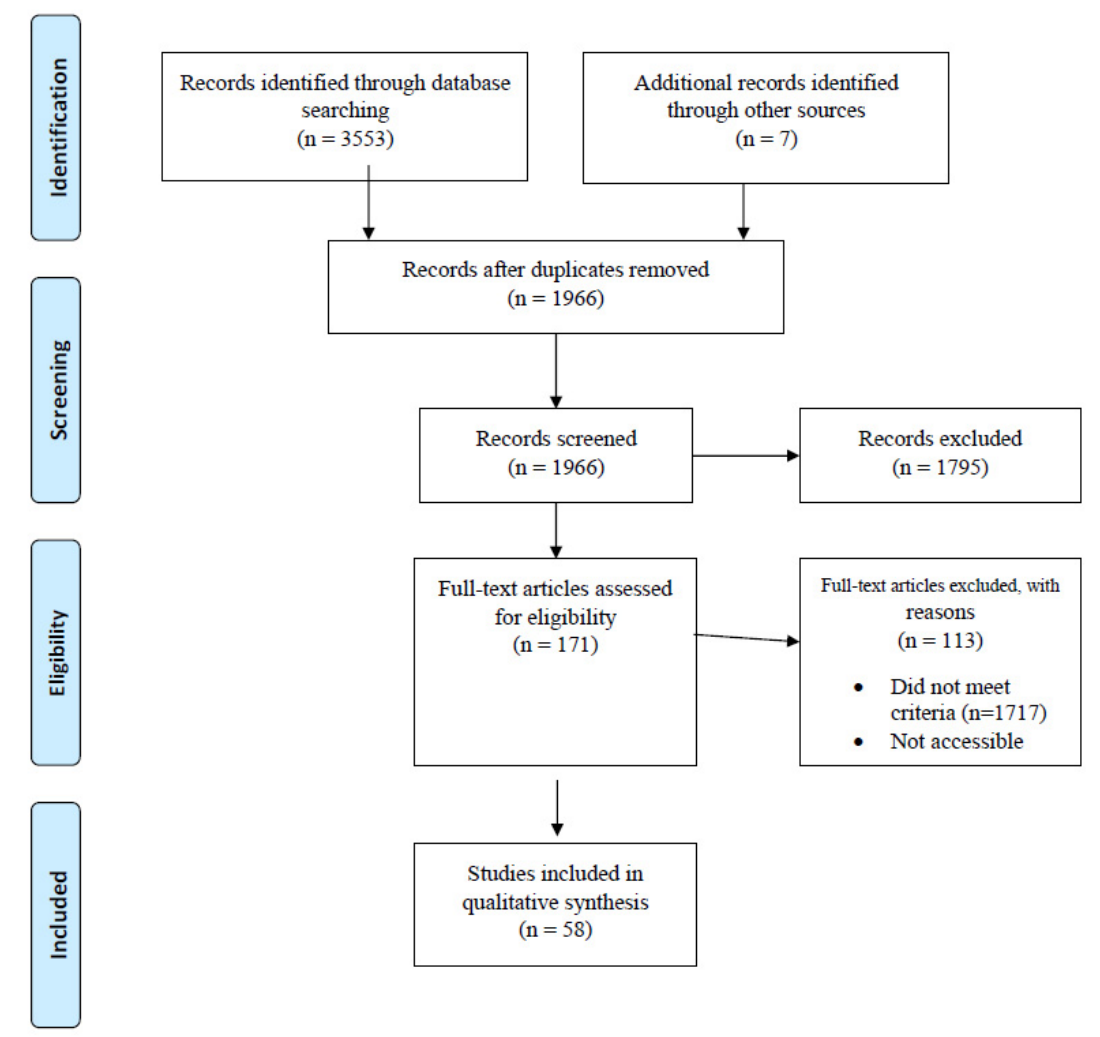

Figure 1. Preferred Reporting Items for Systematic Reviews and Meta-Analyses (PRISMA) flowchart showing search strategy and selection process for the research articles published between 2008 and 2018 used in the current study. Based on the search strategy, 3553 English articles were identified in total. Duplicates were removed.

\subsection{Search Strategy and Data Collection/Extraction}

In August 2018, we searched the English literature published between 2008 and 2018 on three scientific database search engines (PubMed, Web of science and Science Direct) for relevant articles using the search terms (Bacterial zoonoses OR zoonotic bacterial pathogens) AND (Africa) for articles published between January 2008 and August 2018. Other related articles that arose during the search, 
including bibliographies from selected papers were reviewed and added as additional information sources. Duplicate entries were identified and removed before the final selection of articles. Studies that did not meet the predetermined inclusion criteria were removed and included those outside the scope of Africa, nonbacterial zoonoses, conducted/published before 2008, non-English language, reviews, abstracts and conference proceedings. Citations were compiled and deduplicated using EndNote (Thomson Reuters, New York, NY, USA).

\subsection{Data Screening}

The full texts of retrieved articles were screened for inclusion. Studies were selected for evaluation if they met the following inclusion criteria.

- Any research article published between January 2008 and August 2018 that discusses bacterial zoonoses in Africa in both humans and animals.

- Any article that describes information relating to the occurrence (including outbreaks), diagnosis and control of bacterial zoonoses from any country, as defined by the United Nations (UN), within the stated period. Bacterial zoonoses/zoonotic bacterial pathogens were selected for inclusion based on the classification given by the individual studies.

Articles classified as eligible for inclusion were retrieved in full text format and were assessed using the case definitions specified by the respective studies (Table 1). Only accessible articles were screened. Studies were included if they reported on data from any country in Africa within the United Nations (UN) definition of Africa [17]. Only diseases/pathogens that routinely involve animal to human transmission were considered. Pathogens such as Escherichia coli and Staphylococcus aureus, which may or may not involve animal reservoirs, were excluded.

\subsection{Data Analysis}

The statistical analysis was carried out using SPSS version 25 [18] and R software version 3.5.2. [19]. 
Table 1. Case definitions in humans and animals.

\begin{tabular}{|c|c|c|c|c|}
\hline \multirow{2}{*}{$\begin{array}{c}\text { Disease } \\
\text { Brucellosis }\end{array}$} & \multicolumn{3}{|c|}{ Criteria } & \multirow[t]{2}{*}{ Reference } \\
\hline & Confirmed & Probable & & \\
\hline & $\begin{array}{l}\text { Positive qPCR results or positive RBPT results confirmed by positive } \\
\text { ELISA results }\end{array}$ & & & [20] \\
\hline & Blood culture or a $\geq 4$-fold increase in microagglutination test titre & Single reciprocal titre $\geq 160$ & & [21] \\
\hline & Presumptive acute brucellosis & Probable prior brucellosis exposure & & \\
\hline & $\begin{array}{l}\text { Positive ELISA } \\
\text { IgM antibodies result for B. abortus }\end{array}$ & Positive anti-Brucella IgG ELISA result & & [22] \\
\hline \multirow[t]{4}{*}{$Q$ fever } & Acute $Q$ fever & Chronic $Q$ fever & Exposed & \\
\hline & $\begin{array}{l}\text { Evidence criteria consistent with clinical evidence and supported by laboratory } \\
\text { results indicated by elevated levels of ELISA IgG phase I and phase II } \\
\text { antibodies and confirmed by IFA assay showing C. burnetii phase II antibodies } \\
\text { titres of }>1: 128 \text { or qPCR detection of Coxiella DNA }\end{array}$ & $\begin{array}{l}\text { Cases with elevated ELISA IgG phase I } \\
\text { antibodies and IFA assay phase I } \\
\text { antibodies titres of } \geq 1: 800 \text {. }\end{array}$ & & [23] \\
\hline & Clinical symptoms confirmed by qPCR targeting the IS1111 andIS30A spacers & & & [24] \\
\hline & $\begin{array}{l}\text { A } \geq 4 \text {-fold increase in immunoglobulin (Ig) G IFA titre to Coxiella burnetii phase } \\
\text { II antigen }\end{array}$ & & $\begin{array}{l}\text { Titre } \geq 1000 \text { to Phase I antigen or } \geq 64 \text { to } \\
\text { Phase II antigen on either sample } \\
\text { defined } Q \text { fever exposure among those } \\
\text { serum samples not meeting the case } \\
\text { definition for acute } Q \text { fever }\end{array}$ & [25] \\
\hline \multirow[t]{2}{*}{$\begin{array}{l}\text { Spotted fever group rickettsiosis } \\
\text { (SFGR) and typhus group } \\
\text { rickettsiosis (TGR) }\end{array}$} & Acute & & Exposed & \\
\hline & $\mathrm{A} \geq 4$-fold increase in IgG IFA titre to Rickettsia conorii or Rickettsia typhi antigen & & $\begin{array}{l}\text { Titre to } R \text {. conorii or } R \text {. typhi } \geq 64 \text { defined } \\
\text { SFGR or TGR exposure, respectively, } \\
\text { among samples that did not meet case } \\
\text { definition for acute }\end{array}$ & [25] \\
\hline \multirow[t]{6}{*}{ Leptospirosis } & Acute & Presumptive acute leptospirosis & Probable prior leptospirosis exposure & \\
\hline & A MAT cut-off titre of $\geq 1: 160$ & $\begin{array}{l}\text { Positive IgM antibodies result for } \\
\text { Leptospira }\end{array}$ & $\begin{array}{l}\text { Positive anti-Leptospira IgG ELISA } \\
\text { result }\end{array}$ & [22] \\
\hline & Microagglutination test (MAT) $>400$ & IgM-positive/MAT $<400$ & & [26] \\
\hline & Confirmed Leptospira infection & Probable leptospirosis & Exposure to pathogenic leptospires & \\
\hline & $\mathrm{A} \geq$ four-fold increase in MAT titre & MAT titre $\geq 800$ & Titre $\geq 100$ & [27] \\
\hline & $\begin{array}{l}\text { Positive culture detection of Leptospira and/or positive PCR-specific assay for } \\
\text { pathogenic Leptospira spp. Also, pathogenic serovar titre } \geq 200 \text { considered } \\
\text { positive by MAT }\end{array}$ & & & [28] \\
\hline \multirow[t]{2}{*}{ Plague } & Confirmed & Suspected & Probable & \\
\hline & $\begin{array}{l}\text { clinically compatible acute illness with isolation of } Y \text {. pestis from a clinical } \\
\text { specimen } O R>1 \text { positive antibody titre against the } F 1 \text { antigen of } Y \text {. pestis }\end{array}$ & $\begin{array}{l}\text { Clinically compatible acute illness } \\
\text { without laboratory confirmation }\end{array}$ & $\begin{array}{l}\text { Suspected case linked } \\
\text { epidemiologically to a confirmed case } \\
\text { OR suspected case with further } \\
\text { nonconfirmatory laboratory evidence } \\
\text { of plague infection }\end{array}$ & [29] \\
\hline \multirow[t]{2}{*}{ Tularaemia } & Positive & Negative & & \\
\hline & optical density > 0.25 (ELISA) & $\begin{array}{l}\text { optical density }<0.20 \text { were } \\
\text { considered negative }\end{array}$ & & [30] \\
\hline
\end{tabular}




\subsection{Quality Assessment and Data Extraction}

Two independent researchers conducted full texts analysis of each publication using a data extraction form to extract predetermined qualitative and quantitative data; inconsistencies were decided by consensus. Data that consisted of sample size, infection prevalence, diagnosis/investigations, disease/pathogen, host/vector, country and year of study/publication were extracted from included eligible articles and compiled. The independent researchers examined eligibility of studies according the following criteria: appropriate description of study design which guaranteed the quality of the methodology, description of population and sample size for epidemiological studies and strength of association for studies reporting on risk for human infection. Articles were excluded if there was insufficient information in the methodology to decide if criteria were met. Studies that satisfied requirements for quality assessment were considered of enough quality to provide evidence of bacterial zoonoses in different host populations or probable predisposing risk factors.

\subsection{Ethical Approval}

This article does not contain any experimental studies involving human participants or animals performed by any of the authors. Parts of the manuscript involving data from ongoing research projects where ethical approvals were obtained from the Animal Research Ethics Committee of the University of KwaZulu-Natal (Reference: AREC 071/017 and AERC 014/018). The field sampling protocols, samples collected from animals and the research were conducted in full compliance with Section 20 of the Animal Diseases Act of 1984 (Act No 35 of 1984) and were approved by the South African Department of Agriculture, Forestry and Fisheries DAFF (Section 20 approval reference number 12/11/1/5 granted to Prof Dr. ME El Zowalaty).

\section{Results}

\subsection{Data Acquisition}

The preliminary database search yielded 3553 results. Manual search identified seven additional articles. Deduplication yielded 1966 unique articles. Reports were considered duplicated if they had the same information in the author, year of publication, name of the peer review, volume issue and page number fields. After removal of papers that did not meet the inclusion criteria, 58 papers were left for data extraction and qualitative analysis (Table 2). These included 15 articles reporting on Brucella spp. [20-22,31-42]; nine reporting on Leptospira spp. [22,26-28,43-47]; 13 reporting on Coxiella burnetii [23-25,39-41,48-54]; five on Mycobacterium bovis [42,55-58]; eight on Rickettsia spp. [25,53,54,59-63]; five reporting on Anaplasma spp. [53,63-66]; two each on Bartonella spp. [67,68] and Borrelia spp. [69,70]; one each reporting on Yersinia pestis [29], Bacillus anthracis [71], Francisella tularensis [30], Ehrlichia canis [53] and Burkholderia pseudomallei [40]; and six studies reporting on other zoonotic pathogens including Salmonella [72-75] and Campylobacter [76,77] (Table 2). Fourteen studies reported on human zoonoses, 33 were reports on animals, while 11 studies reported on both humans and animals (Table 2). 
Table 2. Diagnoses, sources and study outcomes of bacterial zoonoses in Africa between 2008 and 2018.

\begin{tabular}{|c|c|c|c|c|c|c|c|c|}
\hline Country & $\begin{array}{l}\text { Period of } \\
\text { Study }\end{array}$ & Year of Publication & Disease/Pathogen & Host/Vector/Source & Diagnostic Test/Investigations & $\begin{array}{c}\text { Number of } \\
\text { Animals/Humans/Samples } \\
\text { Tested }\end{array}$ & $\begin{array}{l}\text { Study Outcome/Disease } \\
\text { Frequency/Seroprevalence }\end{array}$ & Reference \\
\hline \multicolumn{9}{|c|}{ NORTHERN AFRICA } \\
\hline Algeria & 2011-2013 & 2016 & $\begin{array}{l}\mathrm{Q} \text { fever (Coxiella } \\
\text { burnetii) }\end{array}$ & $\begin{array}{l}\text { Small ruminant flocks } \\
\text { (aborted females) }\end{array}$ & $\begin{array}{l}\text { Indirect ELISA, real time PCR } \\
\text { (q-PCR) }\end{array}$ & $\begin{array}{l}494 \text { samples (227 sera and } 267 \\
\text { genital swabs) }\end{array}$ & $\begin{array}{l}\text { C. burnetii seroprevalence was } 14.1 \% \text {. } \\
\text { Bacterial excretion observed in } 60 \% \text { of } \\
\text { flocks whiles } 21.3 \% \text { of females showed } \\
\text { evidence of C. burnetii shedding. }\end{array}$ & [49] \\
\hline Egypt & 2008-2009 & 2014 & $\begin{array}{c}\text { Lyme } \\
\text { borreliosis/Borrelia } \\
\text { burgdorferi }\end{array}$ & Cattle, dogs, humans & $\begin{array}{l}\text { Culture, PCR, enzyme-linked } \\
\text { immunosorbent assay (ELISA) }\end{array}$ & $\begin{array}{l}92 \text { samples ( } 15 \text { human blood } \\
\text { samples, } 25 \text { cattle, } 26 \text { dog blood } \\
\text { samples and } 26 \text { ticks) }\end{array}$ & $\begin{array}{l}24 \text { out } 77 \text { non-human samples ( } 51 \\
\text { blood and } 26 \text { tick) positive for the } \\
\text { OspA gene. } \\
\text { All human serum samples positive for } \\
\text { IgM against } B \text {. burgdorferi }\end{array}$ & [69] \\
\hline Egypt & 2014 & 2014 & Brucella spp. & Cattle, buffaloes & iELISA, qPCR & 215 unpasteurised milk samples & $\begin{array}{l}34(16 \%) \text { samples were positive for } \\
\text { anti-Brucella antibodies (iELISA) } \\
\text { whiles qPCR detected Brucella-specific } \\
\text { DNA from } 17 \text { (7.9\%) milk samples. }\end{array}$ & [33] \\
\hline Egypt & 2015 & 2015 & Brucella abortus & $\begin{array}{l}\text { Cows, buffaloes, Egyptian } \\
\text { Baladi goats and ewe }\end{array}$ & RBT, CFT, ELISA & $\begin{array}{l}25 \text { serum samples from aborted } \\
\text { animals }\end{array}$ & $\begin{array}{l}\text { All } 25 \text { samples positive by PCR, but } 10 \\
\text { positive by serology. B. abortus DNA } \\
\text { was detected in all serum samples } \\
\text { taken from buffaloes, goats, ewe and } \\
\text { cows. }\end{array}$ & [35] \\
\hline Egypt & 2015 & 2015 & Leptospirosis & $\begin{array}{c}270 \text { rats, } 168 \text { dogs, } 625 \\
\text { cows, } 26 \text { buffaloes, } 99 \\
\text { sheep, } 14 \text { horses, } 26 \\
\text { donkeys and } 22 \text { camels, } \\
\text { humans and water sources }\end{array}$ & Culture, PCR and MAT. & $\begin{array}{l}\text { Samples from } 1250 \text { animals, } 175 \\
\text { human contacts and } 45 \text { water } \\
\text { sources }\end{array}$ & $\begin{array}{l}\text { Leptospira isolation rates were } 6.9 \% \text {, } \\
11.3 \% \text { and } 1.1 \% \text { for rats, dogs and } \\
\text { cows, respectively. PCR detection } \\
\text { rates were } 24 \%, 11.3 \% \text { and } 1.1 \% \text { for } \\
\text { rats, dogs and cows, respectively. }\end{array}$ & [28] \\
\hline Egypt & 2016 & 2016 & $\begin{array}{l}\text { Bovine brucellosis } \\
\text { (Brucella abortus) }\end{array}$ & cattle & $\begin{array}{c}\text { Culture and biochemical tests, } \\
\text { PCR, RBT, serum agglutination test } \\
\text { (SAT), complement fixation test } \\
\text { (CFT) }\end{array}$ & $\begin{array}{l}\text { Samples selected from an outbreak } \\
\text { in which } 21 \text { out of } 197 \text { pregnant, } \\
\text { previously vaccinated cows } \\
\text { aborted. }\end{array}$ & $\begin{array}{l}\text { Two B. abortus biovar (bv.) } 1 \text { smooth } \\
\text { and two B. abortus rough strains } \\
\text { detected }\end{array}$ & [31] \\
\hline Egypt & 2015 & 2016 & $\begin{array}{c}\text { Salmonella enterica } \\
\text { serovar Typhimurium }\end{array}$ & Chicken meat and humans & $\begin{array}{l}\text { Culture, antimicrobial sensitivity } \\
\text { testing, PCR. }\end{array}$ & $\begin{array}{l}700 \text { samples ( } 500 \text { fresh chicken } \\
\text { meat samples, } 100 \text { hand swab and } \\
\text { stool samples each from workers) }\end{array}$ & $\begin{array}{l}\text { Seventy-eight }(11.1) \text { of samples were } \\
\text { Salmonella isolates, of which } 18 \text { were } \\
\text { from humans and } 60 \text { from chicken } \\
\text { samples). The virulence genes stn, } \\
\text { avrA, mgtC, inva and } b c f C \text { were } \\
\text { detected in all screened isolates }\end{array}$ & [75] \\
\hline Egypt & 2017 & 2017 & $\begin{array}{l}\text { Q fever (Coxiella } \\
\text { burnetii) }\end{array}$ & $\begin{array}{l}\text { Small ruminants and } \\
\text { humans }\end{array}$ & Serological assay & $\begin{array}{l}183 \text { samples (109 sheep, } 39 \text { goats } \\
\text { and } 35 \text { humans) }\end{array}$ & $\begin{array}{l}\text { Seroprevalence of } \text { C. burnetii IgG } \\
\text { antibodies were } 25.71 \%, 28.20 \% \text { and } \\
25.68 \% \text { in humans, goats and sheep, } \\
\text { respectively }\end{array}$ & [50] \\
\hline Egypt & 2016 & 2017 & $\begin{array}{l}\text { Q fever (Coxiella } \\
\quad \text { burnetii) }\end{array}$ & $\begin{array}{c}27 \text { sheep, } 29 \text { goats, } 26 \text { cattle, } \\
26 \text { buffaloes }\end{array}$ & Nested PCR, ELISA & $\begin{array}{l}108 \text { aborted dairy animals, } 56 \\
\text { human contacts }\end{array}$ & $\begin{array}{l}3.4 \% \text { prevalence in goats, } 0.9 \% \text { overall } \\
\text { prevalence, } 19 \% \text { prevalence in humans } \\
\text { examined }\end{array}$ & [48] \\
\hline Sudan & $2007-2009$ & 2013 & Bovine tuberculosis & Cattle & Microscopy, culture, PCR & 6680 bovine carcasses & Bovine TB infection rate was $0.18 \%$. & [55] \\
\hline Tunisia & 2015 & 2017 & $\begin{array}{l}\text { Anaplasma platys-like } \\
\text { infection }\end{array}$ & Goats, sheep and cattle & $\begin{array}{l}\text { Restriction Enzyme Fragment } \\
\text { Length Polymorphism (RFLP) } \\
\text { assay, hemi-nested groEL PCR }\end{array}$ & 963 domesticated ruminants & $\begin{array}{l}\text { Prevalence rates were } 22.8,11 \text { and } 3.5 \% \\
\text { in goats, sheep, and cattle, respectively. }\end{array}$ & [65] \\
\hline
\end{tabular}


Table 2. Cont

\begin{tabular}{|c|c|c|c|c|c|c|c|c|}
\hline Country & Period of Study & Year of Publication & Disease/Pathogen & Host/Vector/Source & Diagnostic Test/Investigations & $\begin{array}{c}\text { Number of } \\
\text { Animals/Humans/Samples } \\
\text { Tested } \\
\end{array}$ & $\begin{array}{l}\text { Study Outcome/Disease } \\
\text { Frequency/Seroprevalence }\end{array}$ & Reference \\
\hline \multicolumn{9}{|c|}{ WESTERN AFRICA } \\
\hline Benin & 2011 & 2016 & $\begin{array}{l}\text { Spotted fever group } \\
\text { rickettsiae }\end{array}$ & $\begin{array}{l}\text { Amblyomma } \\
\text { variegatum }\end{array}$ & PCR. & 910 ticks & $\begin{array}{l}\text { Nearly one-third }(29.4 \%) \text { of samples }(267 / 910) \\
\text { were positive for the SFG rickettsia-specific ompA } \\
\text { gene, whereas } 63.4 \% \text { were positive by } 16 \mathrm{~S} \text { rDNA } \\
\text { gene amplification }\end{array}$ & [60] \\
\hline $\begin{array}{l}\text { Burkina Faso, } \\
\text { Togo }\end{array}$ & 2011-2012 & 2013 & $\begin{array}{l}\text { Brucellosis and Q } \\
\text { Fever }\end{array}$ & $\begin{array}{l}\text { Humans and } \\
\text { livestock }\end{array}$ & $\begin{array}{l}\text { RBT, ELISA, immunofluorescence } \\
\text { assay (IFA) }\end{array}$ & $\begin{array}{l}683 \text { people, } 596 \text { cattle, } 465 \\
\text { sheep and } 221 \text { goats, } 464 \\
\text { transhumant cattle from } \\
\text { Burkina Faso }\end{array}$ & $\begin{array}{l}7 \text { Brucella seropositive in humans, } 9.2 \% \\
\text { seropositivity in village cattle, } 7.3 \% \text { in } \\
\text { transhumant cattle and } 0 \% \text { in small ruminants }\end{array}$ & [41] \\
\hline Côte d'Ivoire & 2012-2014 & 2017 & Brucellosis, Q Fever & $\begin{array}{l}\text { Livestock and } \\
\text { humans }\end{array}$ & $\begin{array}{l}\text { Rose Bengal Test (RBT), indirect } \\
\text { and competitive ELISAs for the } \\
\text { respective pathogens }\end{array}$ & $\begin{array}{l}633 \text { cattle, } 622 \text { small } \\
\text { ruminants and } 88 \\
\text { humans }\end{array}$ & $\begin{array}{l}\text { Human seroprevalence for Brucella spp. was } \\
5.3 \% \text {., } 4.6 \% \text { seroprevalence in cattle adjusted for } \\
\text { clustering. Q Fever seroprevalence was } 13.9 \% \text { in } \\
\text { cattle, } 9.4 \% \text { in sheep and } 12.4 \% \text { in goats. }\end{array}$ & [39] \\
\hline The Gambia & 2014 & 2017 & Q fever & $\begin{array}{l}\text { Humans and small } \\
\text { ruminants }\end{array}$ & ELISA, PCR & $\begin{array}{l}599 \text { human serum and } \\
615 \text { small ruminant } \\
\text { serum samples }\end{array}$ & $\begin{array}{l}24.9 \text { seropositivity rate in small ruminants, and } \\
3.8-9.7 \% \text { in adults depending on ELISA test cut off }\end{array}$ & [51] \\
\hline Ghana & 2012 & 2012 & Bartonella species & Bat flies & Culture and PCR analysis & 137 adult flies & Bartonella DNA was found in $66.4 \%$ of specimen & [68] \\
\hline Guinea & 2011 & 2014 & Brucellosis & Cattle & $\mathrm{RBT}, \mathrm{CFT}$ & 300 serum samples & $\begin{array}{l}\text { 29/300 RBT-positive, } 26 \text { of which were confirmed } \\
\text { by CFT. Mean brucellosis prevalence for } 2 \\
\text { communities was } 8.67 \% \text {. }\end{array}$ & [37] \\
\hline Mali & 2007-2011 & 2012 & $\begin{array}{l}\text { Tick-borne relapsing } \\
\text { fever/ Borrelia } \\
\text { crocidurae }\end{array}$ & $\begin{array}{l}\text { Ornithodoros sonrai } \\
\text { ticks, rodents and } \\
\text { shrews. }\end{array}$ & $\begin{array}{l}\text { Microscopy, serology } \\
\quad \text { (immunoblot) }\end{array}$ & $\begin{array}{l}663 \text { rodents, } 63 \text { shrews } \\
\text { and } 278 \text { ticks }\end{array}$ & $\begin{array}{l}\text { Seroprevalence of Borrelia was } 11.0 \% \text { and } 14.3 \% \text { in } \\
\text { rodents and shrews respectively }\end{array}$ & [70] \\
\hline Niger & 2009-2011 & 2015 & Leptospirosis & $\begin{array}{l}\text { Arvicanthis niloticus, } \\
\text { Cricetomys gambianus, } \\
\text { Mastomys natalensis, } \\
\text { Mus musculus and } \\
\text { Rattus rattus }\end{array}$ & $\begin{array}{l}\text { qPCR, 16S-based metabarcoding, } \\
\text { rrs gene sequencing, VNTR }\end{array}$ & 578 samples & $\begin{array}{l}\text { Leptospires not detected in } R \text {. rattus and Mastomys } \\
\text { natalensis, but Leptospira kirschneri was detected in } \\
\text { Arvicanthis niloticus and Cricetomys gambianus }\end{array}$ & [46] \\
\hline Nigeria & 2012 & 2014 & Bovine tuberculosis & Cattle & Ziehl-Neelsen test, duplex PCR & 168 lung samples & $\begin{array}{l}\text { Prevalence of Mycobacterium tuberculosis was } \\
21.4 \% \text { (AFB test) and } 16.7 \% \text { (duplex PCR), } 81.8 \% \\
\text { of lungs with lesions were positive whiles } 6.7 \% \text { of } \\
\text { lungs without lesions were positive for AFB. }\end{array}$ & [58] \\
\hline Nigeria & 2012-2013 & 2014 & Bartonella Species & Bats and Bat Flies & qPCR, DNA sequencing & $\begin{array}{l}148 \text { bats and } 34 \text { bat flies } \\
\text { samples }\end{array}$ & $\begin{array}{l}51.4 \% \text { of bat blood samples and } 41.7 \% \text { of bat flies } \\
\text { tested were positive for Bartonella spp. DNA. The } \\
\text { prevalence by culture of Bartonella spp. among } 5 \\
\text { bat species ranged from } 0 \% \text { to } 45.5 \% \text {. }\end{array}$ & [67] \\
\hline Nigeria & 2014 & 2015 & $\begin{array}{l}\text { Bovine tuberculosis } \\
\text { (Mycobacterium bovis) }\end{array}$ & Cattle & PCR, Ziehl-Neelsen (ZN) staining & $\begin{array}{l}800 \text { slaughtered cattle } \\
\text { samples }\end{array}$ & $\begin{array}{l}120 \text { samples classified as suspected bTB at } \\
\text { postmortem, } 29.2 \% \text { and } 8.3 \% \text { of which were } \\
\text { bTB-positive by ZN and PCR respectively }\end{array}$ & [56] \\
\hline Nigeria & 2007-2012 & 2016 & Bovine tuberculosis & Cattle & N/A & $\begin{array}{l}52,262 \text { slaughtered cattle } \\
\text { samples }\end{array}$ & $\begin{array}{l}\text { 11.2\% showed signs of tuberculosis lesion at post } \\
\text { mortem. Average yearly prevalence of bTB was } \\
9.1 \% \text {. }\end{array}$ & [57] \\
\hline Nigeria & 2011, 2015 & 2018 & $\begin{array}{l}\text { Coxiella burnetii and } \\
\text { Rickettsia conorii }\end{array}$ & Rodents, fleas & PCR & $\begin{array}{l}194 \text { peridomestic rodents, } \\
\text { and } 32 \text { associated } \\
\text { ectoparasites }\end{array}$ & $\begin{array}{l}2.1 \% \text { of rodents carried C. burnetii DNA. All } \\
\text { ectoparasites negative for C. burnetii by PCR, } 6.3 \% \\
\text { of the pools of various ectoparasites were positive } \\
\text { for Rickettsia spp. glt } A \text { PCR amplification }\end{array}$ & [54] \\
\hline Senegal & 2008-2009 & 2010 & Rickettsia felis & Humans & qPCR & $\begin{array}{l}204 \text { samples from } 134 \\
\text { patients }\end{array}$ & $\begin{array}{l}\text { Prevalence of spotted fever in all samples was } \\
4.4 \%(9 / 204)\end{array}$ & [61] \\
\hline
\end{tabular}


Table 2. Cont

\begin{tabular}{|c|c|c|c|c|c|c|c|c|}
\hline Country & Period of Study & Year of Publication & Disease/Pathogen & Host/Vector/Source & Diagnostic Test/Investigations & $\begin{array}{c}\text { Number of } \\
\text { Animals/Humans/Samples } \\
\text { Tested }\end{array}$ & $\begin{array}{l}\text { Study Outcome/Disease } \\
\text { Frequency/Seroprevalence }\end{array}$ & Reference \\
\hline \multicolumn{9}{|c|}{ EASTERN AFRICA } \\
\hline Ethiopia & 2007-2008 & 2011 & Brucellosis & Cattle & RBT, CFT & 1623 cattle sera & $\begin{array}{l}3.5 \% \text { and } 26.1 \% \text { of animals and herds tested } \\
\text { respectively had anti-Brucella antibodies. }\end{array}$ & {$[32]$} \\
\hline Ethiopia & 2011-2014 & 2015 & $\begin{array}{l}\text { Spotted fever group } \\
\text { (SFG) rickettsiae }\end{array}$ & $\begin{array}{l}\text { Ixodid ticks collected } \\
\text { from domestic } \\
\text { animals }\end{array}$ & $\begin{array}{l}\text { Quantitative PCR (qPCR) system } \\
\text { targeting the gltA gene }\end{array}$ & 767 ixodid ticks & $\begin{array}{l}\text { Rickettsia africae DNA was detected in } 30.2 \% \text { of } \\
\text { Amblyommma variegatum, } 28.6 \% \text { Am. gemma, } \\
0.8 \% \text { Am. cohaerens }\end{array}$ & [59] \\
\hline Ethiopia & 2013 & 2016 & $\begin{array}{l}\text { Salmonellosis/Salmonella } \\
\text { spp. }\end{array}$ & Dairy cattle & $\begin{array}{l}\text { Culture, biochemical tests, PCR, } \\
\text { antimicrobial susceptibility testing, } \\
\text { serotyping and phage typing }\end{array}$ & 1203 faecal samples & $\begin{array}{l}30 \text { samples positive for Salmonella. Standard } \\
\text { serological agglutination tests identify } 9 \text { different } \\
\text { serotypes, with Salmonella typhimurium }(23.3 \%) \\
\text { being the most dominant }\end{array}$ & [73] \\
\hline Ethiopia & 2015 & 2017 & $\begin{array}{l}\text { Salmonellosis/Salmonella } \\
\text { spp. }\end{array}$ & Dogs & $\begin{array}{l}\text { Culture, antimicrobial } \\
\text { susceptibility testing, serotyping } \\
\text { and phage typing }\end{array}$ & $360 \mathrm{dogs}$ & $\begin{array}{l}42(11.7 \%) \text { Salmonella-positive. } 14 \text { serotypes } \\
\text { detected }\end{array}$ & [74] \\
\hline Kenya & 2009 & 2010 & $\begin{array}{l}\text { Salmonellosis/Salmonella } \\
\text { spp. }\end{array}$ & Pigs & $\begin{array}{l}\text { Biochemical tests, serotyping, } \\
\text { phage typing and PCR }\end{array}$ & 116 samples & $\begin{array}{l}\text { 13.8\% positive for Salmonella, } 35.7 \% \text { of isolates } \\
\text { displayed antimicrobial resistance, } 7.1 \% \\
\text { displayed multidrug resistance }\end{array}$ & [72] \\
\hline Kenya & 2012-2013 & 2015 & Brucellosis & $\begin{array}{l}\text { Humans and animals } \\
\text { (cattle, sheep, camels, } \\
\text { and goats) }\end{array}$ & ELISA & $\begin{array}{l}1088 \text { households } \\
\text { surveyed. } 11,028 \\
\text { livestock (37\% goats, } 28 \% \\
\text { sheep, } 27 \% \text { cattle, and } 8 \% \\
\text { camels) were sampled }\end{array}$ & $\begin{array}{l}\text { Individual human and animal seroprevalence } \\
\text { were } 16 \text { and } 8 \% \text { respectively. Household and herd } \\
\text { prevalence ranged from } 5-73 \% \text {, and } 6-68 \% \text {, } \\
\text { respectively }\end{array}$ & [38] \\
\hline Kenya & 2014-2015 & 2016 & Brucellosis & Humans & $\begin{array}{l}\text { Modified Rose Bengal Plate Test } \\
\text { (RBPT), ELISA, PCR. }\end{array}$ & 1067 patients & $\begin{array}{l}\text { 146/1067 (13.7\%) tested positive for brucellosis. B. } \\
\text { abortus the only Brucella species found using } \\
\text { species-specific qPCR }\end{array}$ & [20] \\
\hline Kenya & 2014-2015 & 2016 & $Q$ fever & Humans & ELISA, IFA, qPCR & 1067 patients & $\begin{array}{l}\text { 19.1\% of sera were seropositive by } \mathrm{qPCR} .16 .2 \% \text { of } \\
\text { patients had acute Q fever. }\end{array}$ & [23] \\
\hline Kenya & 2016 & 2016 & Q fever & Humans and cattle & ELISA & $\begin{array}{l}2049 \text { human serum and } \\
955 \text { cattle serum samples }\end{array}$ & $\begin{array}{l}\text { Overall seroprevalence of Coxiella burnetii was } \\
10.5 \% \text { in cattle and } 2.5 \% \text { in humans }\end{array}$ & [52] \\
\hline Kenya & 2013-2014 & 2017 & Novel Rickettsia & $\begin{array}{l}\text { Adult ticks, nymphs } \\
\text { and larvae }\end{array}$ & PCR & 4297 questing ticks & $\begin{array}{l}\text { Anaplasma phagocytophilum detected in } R \text { R. } \\
\text { maculatus ticks and a first-time detection of } \\
\text { Ehrlichia chaffeensis, Coxiella sp., Rickettsia africae } \\
\text { and Theileria velifera in Am. eburneum ticks }\end{array}$ & [62] \\
\hline Kenya & 2014-2015 & 2017 & $\begin{array}{c}\text { Tularaemia } \\
\text { (Francisella tularensis) }\end{array}$ & Humans & ELISA and Western blot & 730 patients & $\begin{array}{l}71(9.7 \%) \text { were seropositive for } F \text {. tularensis by } \\
\text { ELISA but } 27(3.7 \%) \text { were confirmed by Western } \\
\text { blotting }\end{array}$ & [30] \\
\hline Madagascar & 2010-2012 & 2014 & Leptospira & Small mammals & PCR & 344 samples & 44 samples $(12.8 \%)$ positive for Leptospira spp. & [44] \\
\hline Madagascar & 2011-2013, & 2017 & $\begin{array}{l}\text { Brucellosis (Brucella } \\
\text { spp.), Q fever } \\
\text { (Coxiella burnetii) and } \\
\text { melioidosis } \\
\text { (Burkholderia } \\
\text { pseudomallei) }\end{array}$ & $\begin{array}{l}\text { Human, cattle and } \\
\text { ticks }\end{array}$ & $\begin{array}{l}\text { Specific quantitative real-time PCR } \\
\text { assays (qPCRs) }\end{array}$ & $\begin{array}{l}1020 \text { blood samples from } \\
\text { febrile patients, } 201 \text { Zebu } \\
\text { cattle serum samples and } \\
330 \text { zebu cattle-associated } \\
\text { ticks }\end{array}$ & $\begin{array}{l}15(1.5 \%) \text { of samples were Brucella-positive, and } \\
0 \% \text { for C. burnetii and Bu. Pseudomallei. } \\
\text { Anti-C. burnetii antibodies detected in } 4 \text { zebu } \\
\text { serum samples, but no anti-Brucella antibodies } \\
\text { were detected, } 1 \% \text { of ticks analysed tested } \\
\text { positive for } C . \text { burnetii DNA. }\end{array}$ & [40] \\
\hline $\begin{array}{l}\text { Madagascar, } \\
\text { Union of the } \\
\text { Comoros }\end{array}$ & 2012 & 2012 & Leptospira spp. & Bats & qPCR & $\begin{array}{l}129 \text { bats (52 from } \\
\text { Madagascar and } 77 \text { from } \\
\text { Union of the Comoros) }\end{array}$ & $\begin{array}{l}25 \text { samples were positive by probe-specific qPCR. } \\
\text { There were } 34.6 \% \text { and } 11.7 \% \text { infection rates in } \\
\text { bats from Madagascar and Comoros, respectively. }\end{array}$ & [43] \\
\hline
\end{tabular}


Table 2. Cont

\begin{tabular}{|c|c|c|c|c|c|c|c|c|}
\hline Country & Period of Study & Year of Publication & Disease/Pathogen & Host/Vector/Source & Diagnostic Test/Investigations & $\begin{array}{c}\text { Number of } \\
\text { Animals/Humans/Samples } \\
\text { Tested } \\
\end{array}$ & $\begin{array}{l}\text { Study Outcome/Disease } \\
\text { Frequency/Seroprevalence }\end{array}$ & Reference \\
\hline Malawi & 2011 & 2014 & $\begin{array}{l}\text { Brucellosis and } \\
\text { bovine tuberculosis } \\
\text { (bTB) }\end{array}$ & Cattle & $\begin{array}{l}\text { Competitive ELISA, tuberculin } \\
\text { skin test }\end{array}$ & $\begin{array}{l}156 \text { and } 95 \text { cattle } \\
\text { respectively tested for } \\
\text { brucellosis and bTB }\end{array}$ & $\begin{array}{l}7.7 \% \text { and } 1.1 \% \text { of the } 156 \text { and } 95 \text { cattle respectively } \\
\text { tested positive for brucellosis and bTB }\end{array}$ & [42] \\
\hline Mozambique & 2012-2015 & 2017 & Leptospirosis & Humans & $\begin{array}{l}\text { ELISA, microagglutination test } \\
\text { (MAT) }\end{array}$ & $\begin{array}{l}373 \text { paired serum samples } \\
\text { from febrile patients }\end{array}$ & $\begin{array}{l}\text { 1.3\% had acute leptospirosis (MAT > 400), } 10.2 \% \\
\text { had a presumptive infection (IgM-positive/MAT } \\
<400 \text { ). }\end{array}$ & [26] \\
\hline Tanzania & 2007-2008 & 2011 & Leptospirosis & Humans & MAT, blood culture & 870 patients & $\begin{array}{l}8.8 \% \text { of } 453 \text { paired (acute and convalescent) sera } \\
\text { samples were confirmed leptospirosis, } 3.6 \% \text { of } 832 \\
\text { patients (with } \geq 1 \text { serum sample available) } \\
\text { classified as having probable leptospirosis. }\end{array}$ & [27] \\
\hline Tanzania & 2007-2008 & 2011 & $\begin{array}{l}\text { Q Fever, Rickettsioses } \\
\text { (Spotted Fever Group, } \\
\text { SFGR and Typhus } \\
\text { Group, TGR) }\end{array}$ & Humans & ELISA, culture & $\begin{array}{l}870 \text { patients, } 483 \text { tested } \\
\text { for acute Q fever, } 450 \\
\text { tested for acuteSFGR } \\
\text { and TGR }\end{array}$ & $\begin{array}{l}\text { Infection rates of acute } Q \text { fever, SFGR and TGR } \\
\text { were } 5.0 \%, 8.0 \% \text { and } 0.5 \% \text { respectively. }\end{array}$ & [25] \\
\hline Tanzania & 2007-2008 & 2012 & Brucellosis & Humans & Blood culture, MAT & 870 patients & $\begin{array}{l}455(52.3 \%) \text { had paired sera available. } 16 / 455 \\
(3.5 \%) \text { were confirmed brucellosis, } 830 \text { people had } \\
\geq 1 \text { serum sample of which } 0.5 \% \text { had probable } \\
\text { brucellosis }\end{array}$ & [21] \\
\hline Tanzania & 2013 & 2015 & $\begin{array}{l}\text { Leptospirosis, } \\
\text { brucellosis }\end{array}$ & Humans & MAT, IgM and IgG ELISA & 370 patients & $\begin{array}{l}11.6 \% \text { had presumptive acute leptospirosis, } \\
\text { whiles } 7.0 \% \text { and } 15.4 \% \text { showed presumptive } \\
\text { acute brucellosis due to B. abortus and B. } \\
\text { melitensis, respectively. }\end{array}$ & [22] \\
\hline Tanzania & 2011-2012 & 2015 & Campylobacter & Humans & $\begin{array}{l}\text { Culture, matrix-assisted laser } \\
\text { desorption/ionisation-time-of-flight } \\
\text { (MALDI-TOF) mass spectrometry } \\
\text { and PCR }\end{array}$ & 1195 persons & $\begin{array}{l}\text { 11.4\% Campylobacter-positive. C. jejuni ( } 84.6 \%) \\
\text { was most abundant Campylobacter species, with C. } \\
\text { coli being } 15.4 \% \text {. }\end{array}$ & [76] \\
\hline Tanzania & 2012-2014 & 2018 & Leptospirosis & $\begin{array}{l}\text { Rodents, cattle, goats, } \\
\text { sheep }\end{array}$ & $\begin{array}{l}\text { qPCR, culture, phylogenetic } \\
\text { analysis }\end{array}$ & $\begin{array}{l}452 \text { cattle, } 167 \text { goats, } 89 \\
\text { sheep }\end{array}$ & $\begin{array}{l}7.08 \% \text { of cattle, } 1.20 \% \text { of goats and } 1.12 \% \text { of sheep } \\
\text { carried pathogenic Leptospira infection. No } \\
\text { pathogenic Leptospira infection was found in } \\
\text { rodent species sampled }\end{array}$ & [47] \\
\hline Uganda & 2014 & 2014 & Brucellosis & Humans & $\begin{array}{l}\text { Rapid Plate Agglutination Test, } \\
\text { Standard Tube Agglutination Test } \\
\text { (STAT), cELISA }\end{array}$ & $\begin{array}{l}329 \text { individuals (161 } \\
\text { exposed cattle keepers } \\
\text { and } 168 \text { individuals } \\
\text { attending HIV testing). }\end{array}$ & $\begin{array}{l}\text { Brucellosis seroprevalence in exposed cattle } \\
\text { keepers and consumers of raw milk were } 5.8 \% \\
\text { and 9\%, respectively. }\end{array}$ & [36] \\
\hline Uganda & 2012-2013 & 2016 & Brucellosis & Pigs & ELISA, CFT & 1665 serum samples & $\begin{array}{l}3 \text { samples Brucella-positive by ELISA, which were } \\
\text { in turn Brucella-negative by CFT. SAT detected } \\
\text { anti-Yersinia enterocolitica antibodies in } 2 \text { samples }\end{array}$ & [34] \\
\hline Uganda & $2008-2016$ & 2017 & Plague (Yersinia pestis) & Humans & Culture, bacteriophage lysis & 255 suspected cases & $78(31 \%)$ as confirmed per specified criteria & [29] \\
\hline Zambia & 2011 & 2012 & Anthrax & $\begin{array}{l}\text { Humans, } \\
\text { hippopotamuses }\end{array}$ & Culture, PCR & $\begin{array}{l}56 \text { samples from human } \\
\text { patients, hippopotamuses } \\
\text { and soil. }\end{array}$ & $\begin{array}{l}30.4 \% \text { of samples were culture-positive. All } \\
\text { isolates tested were resistant to vancomycin while } \\
\text { isolates showed } 100 \% \text { susceptibility to mostly the } \\
\text { penicillins }\end{array}$ & [71] \\
\hline
\end{tabular}


Table 2. Cont

\begin{tabular}{|c|c|c|c|c|c|c|c|c|}
\hline Country & Period of Study & Year of Publication & Disease/Pathogen & Host/Vector/Source & Diagnostic Test/Investigations & $\begin{array}{c}\text { Number of } \\
\text { Animals/Humans/Samples } \\
\text { Tested } \\
\end{array}$ & $\begin{array}{l}\text { Study Outcome/Disease } \\
\text { Frequency/Seroprevalence }\end{array}$ & Reference \\
\hline Zambia & 2008 & 2014 & $\begin{array}{l}\text { Anaplasma } \\
\text { phagocytophilum, } \\
\text { Rickettsia spp. }\end{array}$ & $\begin{array}{l}\text { Yellow baboons (Papio } \\
\text { cynocephalus) and } \\
\text { vervet monkeys } \\
\text { (Chlorocebus } \\
\text { Pygerythrus) }\end{array}$ & PCR & 88 spleen DNA samples & $\begin{array}{l}\text { Anaplasma phagocytophilum and Rickettsia spp. } \\
\text { were detected in } 12(13.6 \%) \text { and } 35 \text { samples } \\
(39.8 \%) \text { respectively. }\end{array}$ & [63] \\
\hline Zambia & 2016 & 2018 & $\begin{array}{c}\text { Anaplasmosis } \\
\text { (Anaplasma platys) }\end{array}$ & Dogs & PCR & 301 blood samples & $9 \%$ prevalence of Anaplasma species & [64] \\
\hline Zimbabwe & 2014 & 2014 & $\begin{array}{l}\text { Anaplasma } \\
\text { phagocytophilum. }\end{array}$ & $\begin{array}{l}\text { Lions (Panthera leo), } \\
\text { Southern African } \\
\text { wildcats, cheetahs } \\
\text { (Acinonyx Jubatus) } \\
\text { and servals }\end{array}$ & PCR & $\begin{array}{l}98 \text { whole blood samples } \\
\text { from } 86 \text { lions, } 6 \text { Southern } \\
\text { African wildcats, } 4 \\
\text { cheetahs and } 2 \text { servals. }\end{array}$ & $\begin{array}{l}\text { Mixed infection of A. phagocytophilum with other } \\
\text { parasitic pathogens observed in } 1 \text { serval and } 1 \\
\text { Southern African wildcat. }\end{array}$ & [66] \\
\hline \multicolumn{9}{|c|}{ SOUTHERN AFRICA } \\
\hline Botswana & 2009-2012 & 2014 & $\begin{array}{c}\text { Leptospirosis } \\
\text { (Leptospira interrogans) }\end{array}$ & $\begin{array}{l}\text { Banded mongoose } \\
\text { (Mungos mungo), } \\
\text { Selous' mongoose } \\
\text { (Paracynictis selousi) }\end{array}$ & PCR & $\begin{array}{l}42 \text { samples ( } 41 \text { banded } \\
\text { mongooses and } 1 \text { Selous' } \\
\text { mongoose }\end{array}$ & $\begin{array}{l}41.5 \% \text { prevalence among banded mongoose, the } \\
\text { one Selous' mongoose sample was } \\
\text { Leptospira-positive }\end{array}$ & [45] \\
\hline Botswana & 2017 & 2018 & Campylobacter spp. & Humans, chickens & $\begin{array}{l}\text { Culture, whole genome } \\
\text { sequencing }\end{array}$ & $\begin{array}{l}20 \text { human samples, } 70 \\
\text { chicken samples }\end{array}$ & $\begin{array}{l}\text { Phylogenetic analysis showed a high a level of } \\
\text { relatedness between Campylobacter isolated from } \\
\text { human and various poultry sources. Resistance } \\
\text { determinants found include tetO }(52 \%) \text {, gyrA-T86 } \\
(47 \%) \text { and } b l a_{O X A-61}(72 \%)\end{array}$ & [77] \\
\hline South Africa & Not stated & 2017 & $\begin{array}{c}\text { Coxiella burnetii, } \\
\text { Ehrlichia canis, } \\
\text { Rickettsia species and } \\
\text { Anaplasma } \\
\text { phagocytophilum-like } \\
\text { bacterium } \\
\end{array}$ & $\begin{array}{l}\text { Rhipicephalus } \\
\text { sanguineus, } \\
\text { Haemaphysalis elliptica } \\
\text { and Amblyomma } \\
\text { hebraeum }\end{array}$ & PCR & $\begin{array}{l}318 \text { ticks from dogs and } \\
\text { cats. } \\
147 \text { pooled DNA samples }\end{array}$ & $\begin{array}{l}\text { Prevalence were } 37 \% \text { (Rickettsia spp.), } 41 \% \\
\text { (Coxiella burnetii), } 18 \% \text { (Ehrlichia or Anaplasma), } \\
18 \% \text { (Anaplasma phagocytophilum-like bacterium) } \\
\text { from pooled DNA samples }\end{array}$ & [53] \\
\hline \multicolumn{9}{|c|}{ STUDIES IN DIFFERENT GEOGRAPHIC LOCATIONS } \\
\hline $\begin{array}{l}\text { Senegal, Mali, } \\
\text { Tunisia, Algeria, } \\
\text { Gabon, and } \\
\text { Morocco }\end{array}$ & 2008, 2010-2012 & 2014 & $\begin{array}{l}\text { Q fever (Coxiella } \\
\text { burnetii) }\end{array}$ & Humans & $\begin{array}{l}\text { qPCR to amplify the IS1111 and } \\
\text { IS30A spacers }\end{array}$ & $\begin{array}{l}1888 \text { febrile patients (1238 } \\
\text { from Senegal, } 100 \text { from } \\
\text { Mali, } 50 \text { from Gabon, } 184 \\
\text { from Tunisia, } 268 \text { from } \\
\text { Algeria and } 48 \text { from } \\
\text { Morocco), } 500 \text { nonfebrile } \\
\text { samples }\end{array}$ & $\begin{array}{l}0.3 \% \text { C. burnetii infection rate in Algeria, } 0.5 \% \text { in } \\
\text { Senegal. No infection detected in Mali, Morocco, } \\
\text { Gabon, and Tunisia. All nonfebrile samples were } \\
\text { negative. }\end{array}$ & [24] \\
\hline
\end{tabular}


These articles reported on the occurrence, diagnostic methods of zoonoses in humans, livestock, companion animals and vectors. The studies varied in terms of methodological designs, sampling methods, sample size and diagnostic criteria. Most of the studies were case reports, while three were outbreak reports $[29,31,71]$. The risk of sampling bias in retrospective seroepidemiological studies may be significant considering that these studies utilised samples collected or submitted to research laboratories and thus did not provide evidence of random sampling.

The prevalence of different bacterial zoonotic diseases in the four geographic regions in Africa is shown in Figure 2. Bartonellosis was the highest prevalent disease (57.73\%) in western Africa and leptospirosis was the highest prevalent (31.17) disease in northern Africa, plague was the highest prevalent $(30.59 \%)$ in eastern region, while rickettsiosis was the highest prevalent $(37 \%)$ in southern Africa.

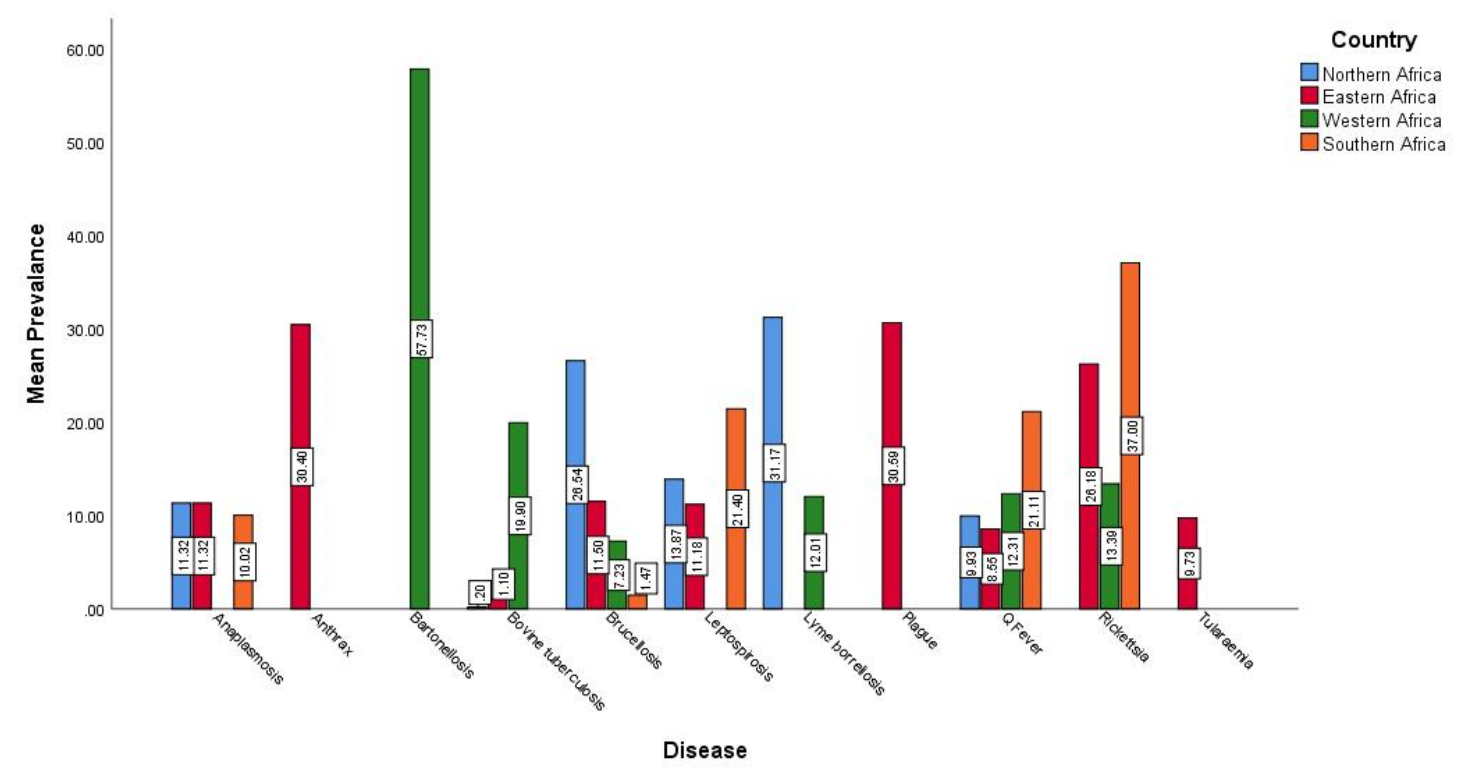

Figure 2. The prevalence of important bacterial zoonotic diseases in different geographic regions in Africa.

As shown in Figure 3, a map of Africa showed the location of the different studies by pathogen in different countries. There was no study that met the inclusion criteria reporting bacterial zoonotic diseases that in central Africa at the time of this review. 


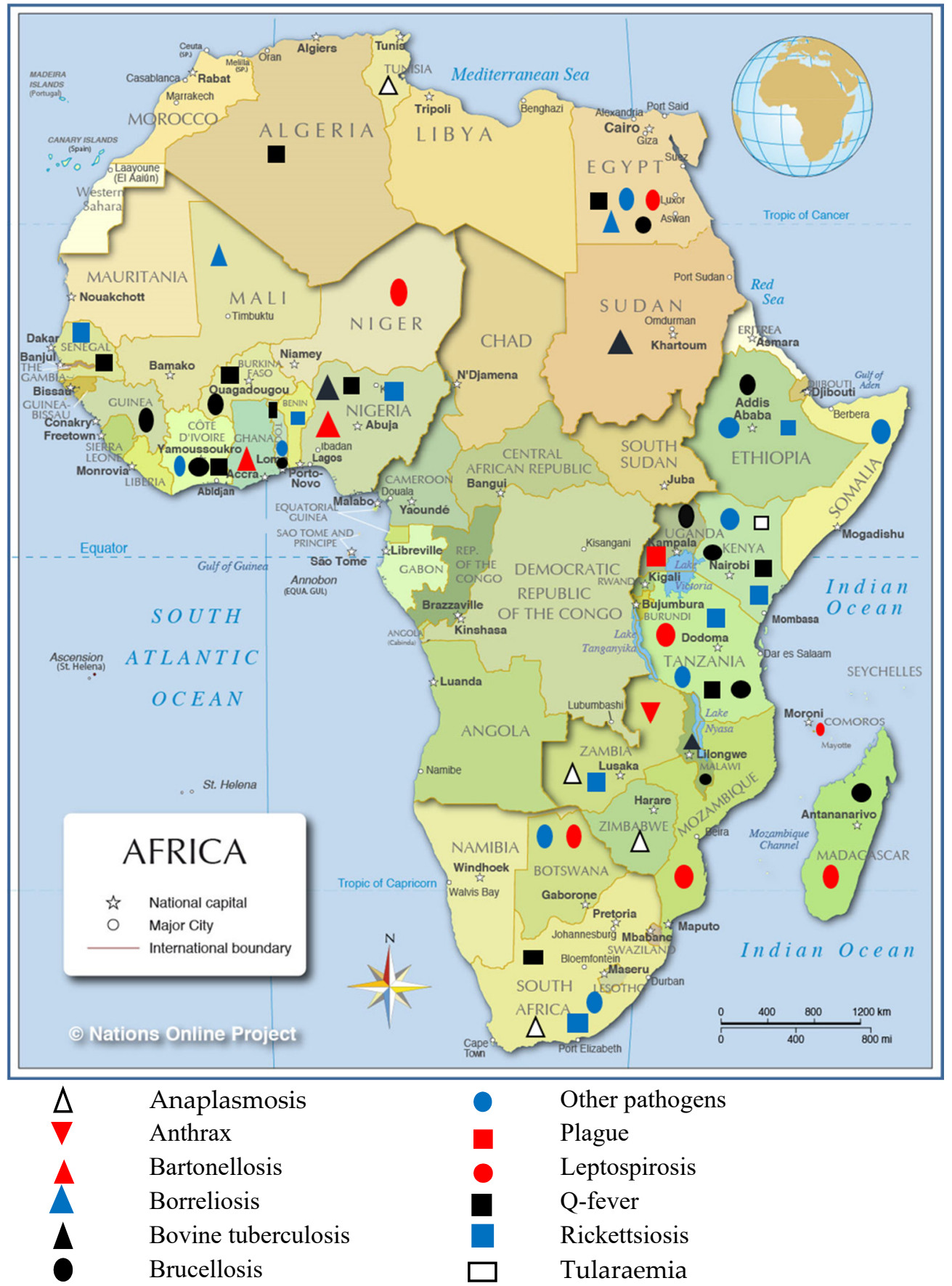

Figure 3. Geographic distribution of important bacterial zoonotic diseases between 2008 to 2018 in Africa. Map of Africa showing locations indicating countries with reported zoonotic diseases and circulation. (Map was reproduced from Nations Online Project.)

\subsection{Brucellosis}

Egypt was the most frequently represented country followed by Kenya and Uganda. The Rose Bengal Test (RBT), complement fixation test (CFT) and enzyme-linked immunosorbent assay (ELISA) were the main diagnostic tests used. Others included culture and biochemical tests, real time PCR (qPCR) and standard microagglutination test (MAT). The prevalence of brucellosis in humans was investigated by four studies including two hospital-based studies $[20,21]$ and two in high risk occupational/population groups [36,39]. Njeru et al. (2016) sought to determine the prevalence of brucellosis in patients in two hospitals in Kenya and to define their clinical characteristics to help 
clinicians identify cases of brucellosis in regions with limited laboratory capacities. It was reported that $13.7 \%$ of samples tested were positive for brucellosis (defined as positive qPCR results or positive RBPT results confirmed by positive ELISA results) [20]. Bouley et al. (2012) also found evidence of brucellosis in $3.5 \%$ of participants screened. There was no diagnosis of brucellosis by the hospital clinical team even though study participants with brucellosis were given antibiotics or antimalarials in the hospital [21]. Using blood samples, Boone et al. (2017), investigated the causes of febrile illness in Madagascar, and found a 1.5\% detection rate for Brucella [40]. It is the first report of brucellosis in febrile patients reported in Madagascar [40]. Chipwaza et al. (2015) investigated the prevalence of bacterial febrile illnesses in Tanzania, and found that $7.0 \%$ and $15.4 \%$ showed presumptive acute brucellosis due to B. abortus and B. melitensis, respectively [22].

In the Uganda study of cattle keepers and consumers of unpasteurised milk, consumption of unpasteurised milk was significantly linked $(p=0.004)$ to seropositivity in one of the districts of the study (Mbarara District). Brucellosis seroprevalence in exposed cattle keepers and consumers of raw milk were $5.8 \%$ and $9 \%$, respectively, in this study [36] (Table 2).

Six articles investigated brucellosis in animals including livestock [31-35,37]. In an outbreak investigation in Egypt, one study investigated the molecular profile of Brucella isolates and found two different profiles of the B. abortus biovar (bv.): one smooth and one rough B. abortus strain, with low genetic diversity identified by the molecular typing method and multiple locus of variable number tandem repeats analysis (MLVA-16) [31]. As risk factors for Brucella infection, Megersa et al. (2011) found that herd size and age of cattle were found to have played roles in a study investigating the prevalence of cattle brucellosis in traditional animal husbandry practice [32].

Large (odd ratio $(\mathrm{OR})=8.0,95 \% \mathrm{CI}=1.9,33.6)$ and medium herds $(\mathrm{OR}=8.1,95 \% \mathrm{CI}=1.9,34.2)$ were found to present a higher risk of infection than small herds. One article investigated the prevalence and risk factors for brucellosis in humans and livestock, and found their individual seroprevalence to be $16 \%$ and $8 \%$, respectively [38]. Risk factors found to affect the odds for human seropositivity in this study included exposure to goats (adjusted odds ratio $(\mathrm{OR})=3.1,95 \% \mathrm{CI}=2.5-3.8$ ), frequent consumption of raw milk ( $\mathrm{OR}=3.5,95 \% \mathrm{CI}=2.8-4.4)$ and handling of animal hide $(\mathrm{OR}=1.8,95 \%$ $\mathrm{CI}=1.5-2.2)$. Again, there was an association between seropositivity in humans and animals, with a six-fold increase observed for humans in households with seropositive animals compared to those without [38].

\subsection{Q Fever}

Three papers investigated the presence of $Q$ fever in human febrile patients [23-25]. The study by Angelakis and colleagues (2014) was conducted in five countries-Senegal, Mali, Tunisia, Algeria, Gabon and Morocco-and recorded infection rates of $0.3 \%$ and $0.5 \%$ in Algeria and Senegal, respectively. For the first time in humans, Coxiella burnetii (causative agent of $\mathrm{Q}$ fever) genotype 35 was found in a patient in Senegal [24]. In the other study in febrile patients, $16.2 \%$ of patients screened had acute Q fever [23] (Table 1). Risk factors for human infection included exposure to goats (OR: 3.74, $95 \%$ CI: 2.52-9.40), cattle (OR: 2.09, 95\% CI: 1.73-5.98) and animal slaughters (OR: 1.78, 95\% CI: 1.09-2.91). Dietary factors linked with seropositivity were found to include consumption of raw milk (OR: 2.49, 95\% CI: 1.48-4.21) and locally fermented milk products (OR: 1.66, 95\% CI: 1.19-4.37). Univariate analyses showed no significant association between county of residence, gender, occupations (except herders) and seropositivity. Using ELISA and culture assays, Prabhu et al. (2011) investigated the occurrence of $Q$ Fever in hospitalised febrile patients in northern Tanzania, and found the infection rate to be $5.0 \%$ [25].

Five articles probed the presence of $Q$ fever in human and animal hosts [41,48,50-52]. Abdel-Moein and Hamza examined vaginal discharges and placental cotyledons from animals that had aborted and found an overall prevalence of $0.9 \%$, with the highest prevalence of $\mathrm{Q}$ fever being found in goats (3.4\%). A seroprevalence of $19 \%$ was detected in the human contacts screened, with a higher prevalence 
being detected in farmers (30.6\%) than veterinarians and veterinary assistants $(9.4 \%)$ [48]. A higher seroprevalence of $25.71 \%$ was found in human contacts in Egypt [50].

In a Gambia study, a $24.9 \%$ seropositivity rate in small ruminants and $3.8-9.7 \%$ in adults, depending on the ELISA test cut off, was reported [51]. Having at least one seropositive animal in a compound was determined to be a risk factor for human seropositivity (OR: 3.35, 95\% CI: 1.09-14.44) [51]. Wardrop et al. (2016) found overall C. burnetii seroprevalence in cattle and humans to be $10.5 \%$ and $2.5 \%$, respectively [52]. There was no correlation between cattle and human seroprevalence. An article investigated the prevalence of $Q$ fever infection in small ruminants after abortion or the lambing period and found a $14.1 \%$ prevalence at individual level and 58.6\% at flock level in Algeria [49]. Excretion of bacteria was found in $60 \%$ of flocks, with $21.3 \%$ of females showing evidence of C. burnetii shedding. Dean and colleagues investigated the seroprevalence of $Q$ fever in humans and livestock in Togo, and found that there was a significantly higher $C$. burnetii seroprevalence among the Fulani people, who also had greater livestock contact (45.5\%, 95\% CI: 37.7-53.6\%) [41].

Real-time PCR (qPCR) and ELISA were the most commonly used diagnostic tests. Another test included indirect immunofluorescence assay (IFA) (Table 2).

\subsection{Leptospirosis}

PCR was the most widely used diagnostic method, being used in six out of the eight studies. Other techniques such as culture isolation, MAT and ELISA were also used. Three articles [22,26,27] studied the seroepidemiology of leptospirosis among febrile patients. In a Morocco study, Ribeiro et al. (2017) observed that $1.3 \%$ of samples had acute leptospirosis defined therein as a microagglutination test (MAT) $>400$, while $10.2 \%$ had a presumptive infection, therein defined as IgM-positive/MAT $<400$. Patients with acute infection had a significantly higher contact with rodents $(100 \%, 5 / 5)$ than those with presumptive $(39.5 \%, 15 / 38)$ or no infection $(41.8 \%, 138 / 330)(p=0.031)$. Although the malaria tests proved negative, $80 \%$ of patients with acute leptospirosis were given antimalarial drugs. In addition, $20.9 \%$ of the confirmed/presumptive cases of leptospirosis occurred in sub-urban populations. Similarly, Biggs et al. (2011), in their study of leptospirosis in febrile patients in northern Tanzania, observed that $8.8 \%$ of paired (acute and convalescent) sera samples were confirmed leptospirosis (defined therein as $\geq$ four-fold increase in MAT titre) and $3.6 \%$ (with $\geq 1$ serum sample available) were classified as having probable leptospirosis (defined therein as MAT titre $\geq 800$ ). The most predominant serotypes were Mini and Australis. There was an association found between Leptospira infection and rural dwelling (OR 3.4, $p<0.001$ ) [27]. Chipwaza et al. (2015) found $11.6 \%$ seroprevalence of presumptive acute leptospirosis among people presenting with febrile illnesses [22].

In a study in Egypt, Leptospira isolation rates were 1.1\%, $6.9 \%$ and $11.3 \%$ for cows, rats and dogs, respectively, whereas PCR detection rates were $1.1 \%, 24 \%$ and $11.3 \%$, respectively [28]. The human contacts who were tested proved negative by culture isolation and PCR. However, using MAT, the seroprevalence of the human samples was determined to be $49.7 \%$. In that study, six Leptospira serovars (Grippotyphosa Pyrogenes, Icterohaemorrhagiae, Canicola, Celledoni and Pomona) were isolated from cows, rats and dogs. These three species of animals were found in this study to be the most important carriers of leptospirosis in Egypt. Of note is the recovery of some isolates from rats caught from dairy farms and water sources supplying the farms [28]. In a survey of an area with a high reported incidence of human leptospirosis in northern Tanzania, Allan et al. (2018) found no proof of Leptospira in rodents sampled randomly in and around households in the area. However, $7.08 \%$ of cattle, $1.20 \%$ of goats and $1.12 \%$ of sheep from local slaughterhouses carried pathogenic Leptospira infection [47]. Similarly, although Rattus rattus and Mastomys natalensis are usual rodent reservoirs for Leptospira, Leptopires was not detected in them, although Leptospira kirschneri was detected in two rodent species, namely, Arvicanthis niloticus and Cricetomys gambianus, which are confined to irrigated cultures in the city [46]. The variable number of tandem repeat (VNTR) profiles showed that the leptospires found did not belong to any previously described serovars. The first published report of L. interrogans in the Banded mongoose (Mungos mungo) and Selous' mongoose (Paracynictis selousi), 
and the only published report of the pathogen in wildlife in Botswana was reported by Jobbins et al. (2014) [45]. In some cases, the prevalence of Leptospira in animals including bats and other small mammals ranged from $11.7 \%$ to $34.6 \%$ [43,44].

\subsection{Bovine Tuberculosis}

A bovine tuberculosis infection rate of $0.18 \%$ was detected in a Sudan study, with prevalence of $4.5 \%$ in slaughtered cattle with caseous lesions [55]. Sa'idu et al. (2014) conducted a study to establish the prevalence of bovine tuberculosis in slaughtered cattle using PCR and Ziehl-Neelsen (ZN) staining and found an overall prevalence rate of $8.3 \%$ [56]. In study of bovine tuberculosis in slaughtered cattle in Nigeria, the prevalence of mycobacterium TB was $21.4 \%$ (acid-fast bacilli test) and $16.7 \%$ (duplex PCR) [58]. The presence of lesions in lungs was highly associated (OR $=52.3 ; 95 \%$ CI: 16.4-191.8) with positive results for acid-fast bacilli (AFB) test compared to those without lesions. A retrospective study at a Nigerian abattoir was conducted with an average yearly bovine tuberculosis prevalence rate of $9.1 \%$ detected [57].

\subsection{Rickettsiosis}

Four articles investigated Rickettsia spp. in ticks [53,59,60,62] and two in humans [25,61]. Prabhu et al. (2011) investigated the occurrence of spotted fever group (SFGR) and typhus group rickettsioses (TGR) in hospitalised febrile patients in northern Tanzania, and found infection rates to be $5.0 \%, 8.0 \%$ and $0.5 \%$, respectively [25]. Kumsa et al. (2015) investigated the transmission of spotted fever group rickettsiae through ixodid ticks and found an overall prevalence to be $6 \%$. Being the first study to investigate SFG rickettsiae in Benin, Moumouni et al. (2016) found that $29.4 \%$ of samples were positive for the SFG rickettsia-specific ompA gene, whereas $63.4 \%$ were positive by $16 \mathrm{~S}$ rDNA gene amplification [60]. In Senegal, a study sought to investigate the cause of reported febrile conditions that had tested negative for malaria [61]. The prevalence of spotted fever in all samples was $4.4 \%$, with was no positive sample recorded for typhus group rickettsiae. By sequencing theamplicons, one sample was found to be R. conorii [61].

\subsection{Anaplasmosis}

Vlahakis et al. (2018) conducted a study to identify and characterize Anaplasma species from dogs in Zambia and found a 9\% prevalence of Anaplasma spp. as detected by PCR. It is the first study to highlight the prevalence of Anaplasma spp. in dogs in Zambia and the first report of Anaplasma platys in Zambia [64]. Said et al. (2017) used a restriction enzyme fragment length polymorphism (RFLP) together with a hemi-nested groEL PCR method to distinguish between A. platys and genetically related strains. Analysis of the sequence variants pointed to infection with an unclassified Anaplasma platys-like strains that were genetically related to A platys, with prevalence rates ranging from $3.5 \%$ to $22.8 \%$ in sheep, goats and cattle [65]. Mtshali and colleagues identified an Anaplasma phagocytophilum-like bacterium in $18 \%$ of pooled DNA samples [53].

\subsection{Lyme Borreliosis}

Elhelw et al. (2014) investigated the occurrence of borreliosis as an emerging zoonotic disease and its zoonotic potential in Egypt [69] and found Borrelia burgdorferi in the animals screened. In addition, the OspA gene (outer surface protein A gene) and anti-B. burgdorferi IgM were detected by PCR and ELISA respectively in human contacts. The use of culture techniques to isolate B. burgdorferi showed low sensitivity as shown by the recovery of only one isolate out of seven samples cultured, while $26.6 \%$ of febrile human blood samples tested were positive by PCR, and 15 out of 15 serum samples tested positive for IgM ELISA. The human contacts had been exposed to tick bites, which suggests a possible zoonotic transfer. In Mali, Borrelia seroprevalence of $11.0 \%$ and $14.3 \%$ in rodents and shrews, respectively, was observed, with $2.2 \%$ of animals displaying active spirochete infections at the time of capture [70]. 


\subsection{Bartonellosis}

In a first report on the occurrence of Bartonella spp. in bats and bat flies from Nigeria, $51.4 \%$ of bat blood samples and $41.7 \%$ of bat flies tested were positive for Bartonella spp. DNA [67]. The prevalence by culture of Bartonella spp. among five bat species ranged from $0 \%$ to $45.5 \%$ [67]. Of 137 adult bat flies studied in Ghana, $66.4 \%$ were positive for Bartonella DNA [68].

\subsection{Plague}

In a suspected plague outbreak in Uganda, 31\% (78 out of 255 suspected cases) of cases were confirmed as plague [29]. The study found a correlation between reports of human plague and a large number of dead rats in a village. Close contacts with rodents, lack of appropriate antibiotics and a delay in seeking medical help contributed to the menace of human plague in the area where the study was conducted [29].

\subsection{Tularaemia}

Among febrile patients seeking treatment at remote hospitals in northeastern Kenya, 9.7\% were seropositive for Francisella tularensis by ELISA, while 3.7\% were confirmed by Western blotting [30]. Most of the febrile cases that tested positive to tularaemia were not recognised by clinicians and the appropriate treatment protocol was not therefore followed. Indeed, most cases were treated with antimalarial agents and/or beta-lactam antibiotics.

\subsection{Anthrax}

In the light of a suspected outbreak of anthrax in Zambia in 2011, a study to investigate the cause was initiated [71]. Human, hippopotamus and soil samples were screened by culture and PCR methods. It was found that $30.4 \%$ of samples were culture-positive. All isolates tested were resistant to vancomycin, but showed $100 \%$ susceptibility to the penicillins [71].

\subsection{Others}

\subsubsection{Salmonella}

In a study probing antimicrobial resistance profile and serotypes of porcine Salmonella isolates from Kenyan slaughterhouses, $13.8 \%$ were Salmonella positive, while $7.1 \%$ of isolates tested showed multidrug resistance [72]. Resistance to tetracycline, ampicillin, chloramphenicol and streptomycin were found to be mediated by the tet(A), bla $a_{T E M}$, cat $A 1$ and $\operatorname{str} A$ genes, respectively [72]. An Ethiopia study recorded a high multidrug resistance value of $36.7 \%$ (to seven or more drugs tested) in Salmonella isolated from dairy cattle [73]. In a study to determine the prevalence, antimicrobial susceptibility profiles and serotype distribution of faecal Salmonella from apparently healthy dogs, Kiflu et al. (2017) found a Salmonella carriage rate of $11.7 \%$ in dogs screened [74]. Fourteen Salmonella serotypes were detected, with the most dominant ones being S. bronx (16.7\%), and S. newport (14.3\%) and 9.5\% for each of S. typhimurium, S. indiana, S. kentucky, S. saintpaul and S. virchow. There was an association between Salmonella infection and diarrhoeal symptoms in the past 60 days. Highest antibiotic resistance rates were shown against oxytetracycline (59.5\%), neomycin (50\%) and streptomycin (38.1\%), with $45.2 \%$ of isolates showing resistance to three or more of the 16 antibiotics tested [74]. Ahmed et al. (2016) detected the virulence genes $s t n, a v r \mathrm{~A}, m g t \mathrm{C}$, inv $\mathrm{A}$ and $b c f \mathrm{C}$ in all screened isolates of Salmonella enterica serovar Typhimurium [75]. Antibiotic resistance frequencies detected were as follows; gentamicin (30\%), ampicillin and tetracycline (53.3\%, each), streptomycin (56.7\%) and trimethoprim-sulfamethoxazole and chloramphenicol (73.3\%, each). Frequencies of resistance genes discovered in Salmonella typhimurium; sul1 (96.7\%), tet $\mathrm{A}(\mathrm{A})(60 \%)$, tet $\mathrm{A}(\mathrm{B})(20 \%)$, floR (73.3\%), aad A1 (46.7\%), aad A2 (63.3\%), blaTEM (53.3\%), aadB $(6.7 \%)$ and $\operatorname{aad} \mathrm{C}(23.3 \%)$ [75]. 


\subsubsection{Campylobacter}

A study was conducted to determine the antimicrobial resistance profile and epidemiology of Campylobacter isolated from humans in Tanzania [76]. The prevalence of Campylobacter infection in human samples was $11.4 \%$. A high resistance rate was found against erythromycin $(84.3 \%)$ and azithromycin $(89.6 \%$ ) whereas a relatively low resistance rate of $22.1 \%$ was found against ciprofloxacin [76]. In a Botswana study, phylogenetic analysis showed that Campylobacter spp. from different poultry and human sources were highly related [77].

\section{Discussion}

In Africa, zoonotic diseases remain to be largely neglected by public health and veterinary services, despite causing a substantial health burden in several countries. This work intends to systematically review data on the most important bacterial zoonoses in Africa, within the period of 2008 to 2018, focusing on the presence, prevalence estimates, causative pathogens, control strategies and risk for human infection. We found 58 studies/reports on 29 countries, which were considered of adequate quality to provide estimates of burden of disease or pathogen, with Egypt (eight), Kenya (seven) and Tanzania (six) being the most represented. We found no reports on zoonotic diseases from central African countries eligible to the inclusion criteria. The distribution of bacterial zoonoses studies in the current study was shown in Figure 3 and was found to be in line with previously reported burden of zoonotic diseases in Africa [78]. Although several bacterial zoonoses such as brucellosis, foodborne diseases, Q-fever, and tuberculosis were reported from countries in central Africa [78,79], we found no reports that were eligible to the inclusion criteria on bacterial zoonotic diseases in this region. The current study reviewed data on the evidence of various zoonoses in humans, multiple species of animals, vectors and the environment. Fourteen reports studied possible bacterial zoonoses in humans (including patients visiting hospitals and high-risk groups), 33 reports investigated zoonoses in animals, whereas 11 reports investigated zoonoses in both humans and animals. Nine reports observed the possible roles of vectors in the transmission of bacterial zoonoses. Vector-borne zoonotic bacterial pathogens carried by vectors (ticks, fleas and bat flies) in this study include Borrelia spp., Rickettsia spp., C. burnetii, Anaplasma spp. and Bartonella spp. The lack of disease surveillance studies and control programs at the national level in most countries introduces a knowledge gap, and makes it difficult to estimate representative disease burden and thoroughly investigate pathogen transmission dynamics. Thus, more national level epidemiological studies ought to be undertaken to bridge this knowledge gap. The epidemiological picture of zoonotic diseases on the African continent is evolving. The prevalence of zoonotic diseases/pathogens summarised in this review must be interpreted with caution, as many of the studies were conducted within specific geographical and occupational settings/groups and may not be extrapolated to the general population. The changing scenes of rapid urbanisations in various countries may translate to the changing epidemiology of zoonotic diseases.

Considering the complex interrelatedness between humans, animals and the environment, any intervention that seeks to tackle the problem of bacterial diseases and antimicrobial resistance from a non-holistic, single focus point of view is bound to fail. The 'One Health' approach seeks to amalgamate and improve the efforts of clinicians, veterinarians, environmentalists, agricultural and public health officials to develop effective surveillance techniques, accompanied by appropriate diagnostic and therapeutic interventions. This holistic and coordinated approach will lead to the enactment of more thorough and effective policies. The achievement of true One-health approach depends of the recognition of the complex interplay between human health, domestic, wild animals, and the environment [78,80-82]. It is crucial to implement the one-health components in low-income and resource-limited countries in Africa to tackle and reduce the increasing threats of bacterial zoonotic infectious diseases [16,83-85] 


\subsection{Brucellosis}

Diagnostic methods most commonly used for brucellosis in developing countries are serologic assays based on rapid slide agglutination tests, albeit the poor specificity of these tests limits their usefulness. Other diagnostic techniques such as ELISA and PCR, were used by most studies on brucellosis $[20,36,38,86]$, are more specific and sensitive, proffering a better correlation with clinical observations, although the latter may not be readily available in many developing countries [87]. The precision of serodiagnosis depends on the presence of antibodies in the serum, and infected animals with low concentrations of antibodies, or no antibodies at all in serum, are therefore likely to present as negative even though they may be infectious [31]. In addition, PCR has the benefit of facilitating the differentiation of Brucella genotypes. Considering that the diagnosis and clinical management of febrile illnesses in most developing countries are done empirically, resulting in inaccurate treatment, it is essential to augment the capacity of laboratories to improve the diagnosis accuracy and treatment reliability. This point is highlighted by the fact that $43.2 \%, 20.5 \%$ and $8.2 \%$ of patients with brucellosis in the study by Njeru et al. (2016) were diagnosed with typhoid fever, malaria and pneumonia, respectively [20]. In Tanzania, as is the case in many developing countries, brucellosis is an underdiagnosed/misdiagnosed and undertreated disease with no standard treatment protocol usually followed in hospitals, as evinced by the misdiagnosis of it as malaria and pneumonia [21]. The absence of specific symptoms makes it difficult to distinguish brucellosis from several other febrile illnesses occurring in the same geographical area. There is the need for heightened clinical alertness and laboratory capacity building to ensure prompt and accurate diagnoses to aid in the detection and subsequent management of brucellosis in this part of the world. Nasinyama et al. (2014) observed that cELISA test had a sensitivity and specificity of $98.3 \%$ and $99.7 \%$, respectively, and is valuable for observing the effectiveness of treatment, prognosis and clinical conditions [36]. Although no single diagnostic test is ideal, with reference to specificity and sensitivity, the standard tube agglutination test (STAT) was preferred in such environments. The limitation of STAT is the long turnaround times, making it unsuitable for seroepidemiological studies, where multiple samples need to be investigated, or in hospital laboratories, where brucellosis therapy has to be initiated quickly. Thus, less time-consuming and faster turnaround diagnostic methods, such as Competitive Enzyme-Linked Assay (cELISA), may need to be used [36].

Although brucellosis has been well recorded in nomadic herdsmen in rural sub-Saharan Africa, owing to their being in close contact with infected animals [88], Bouley et al. (2012) found no association of note between brucellosis and rural residence. While brucellosis prevalence is generally higher in northern Africa [89,90], its seroprevalence ranges from 3 to $8 \%$ in sub-Saharan Africa [91]. Despite the implementation of control regimes and strategies, brucellosis remains pervasive in Egypt. Despite immunisations with Brucella (B.) abortus RB51 vaccine, a rise in abortions suspiciously caused by Brucella was observed in a dairy cattle herd. The disease has serious economic implications resulting from abortions, infertility and decreased milk production, thus necessitating the implementation of surveillance and control strategies to forestall the socioeconomic effects in both developed and developing countries where the disease is endemic. The prevention, control and eradication strategies against brucellosis usually involve vaccination programmes which employ live, attenuated vaccines as they can elicit long-term cell-mediated immunity [92]. Serological testing and the subsequent culling of seropositive animals are crucial interventions in the adequate control of zoonoses in developing countries.

A large herd size leads to increase in stocking volume, thus exposing more animals to infection [93], as demonstrated by Megersa et al. (2011) [32]. Brucella infection in livestock husbandry practice poses zoonotic threats to the public due to close contact with animals, assisting in parturition and the consumption of unpasteurised milk. The study by Osoro et al. (2015) highlights a 'One Health' approach to tackling the menace of brucellosis by concurrently looking into the prevalence of brucellosis in both humans and their livestock in the same household [38]. This approach allows for identification 
and assessment of risk factors for transmission and gives a more complete epidemiological picture and delineates the factors at play at the human-animal interface [38].

\subsection{Q Fever}

Q fever is a common cause of febrile illness in Kenya, but it is underestimated [23]. There is a low level of clinical suspicion, with most febrile patients admitted to hospitals given standard empirical treatments that typically include antimalarials and penicillin antibiotics. Even though Njeru et al. (2016) reported a high $Q$ fever prevalence rate of $16.2 \%$, the most common working diagnosis by clinicians documented in this group was typhoid fever $(45.1 \%)$, followed by acute respiratory infections/pneumonia (37.6\%), malaria (6.9\%) and fever of unknown origin (10.4\%) [23]. There are indications of increasing cases of severe febrile illnesses of under-recognised zoonotic sources facing clinicians, but diagnostic tools for such conditions are lacking in many African countries [94], leading to overdiagnosis of familiar febrile illnesses even when there is no diagnostic evidence to back.

Bok et al. (2017) determined that having at least one seropositive animal (small ruminant) in one's compound was a risk factor for human seropositivity [51], highlighting the relationship between seropositivity and closeness of contact with infected animals. Other studies found risk factors for human infection included exposure to goats, cattle and animal slaughters. Dietary factors linked with seropositivity were found to include consumption of raw milk and locally fermented milk products [23].

The use of point-of-care testing in health care centres will inform treatment and decrease the possibility of wrongful diagnosis and inappropriate treatment in febrile patients seeking treatment at health centres. As shown by Angelakis and colleagues, real-time PCR, which is less time-consuming than conventional PCR, can come in handy in decreasing delays in diagnosis, thereby facilitating prompt treatment [24]. Even though the immunofluorescent assay test (IFAT) is considered the gold standard for serological detection of $Q$ fever, it still falls short and requires highly experienced technicians [52,95]. There is the likelihood that some infected animals may shed bacteria without having antibodies thus they may be classified as negative by serology, leading to an underestimation of associated risk factors. Analysing animals for the shedding ability would partly provide a solution. Excretion of bacteria was found in $60 \%$ of flocks by one study [49], presenting a significant risk in the spread of the disease especially to humans.

\subsection{Leptospirosis}

The possible role of rodents in the transmission of the disease was underscored by the observation that patients with acute infection had a significantly higher contact with rodents than those with presumptive or no infection [26]. Also, a study found an association found between Leptospira infection and rural dwelling (OR 3.4, $p<0.001$ ) [27]. Again, a worrying case of misdiagnosis and subsequent inappropriate treatment was observed, as $80 \%$ of patients with acute leptospirosis were given antimalarial drugs by prescribers in Mozambique [26].

There may be a gradual expansion in the occurrence of leptospirosis from the typical rural communities to sub-urban communities as evidenced by the fact that $20.9 \%$ of the confirmed/presumptive cases of leptospirosis occurred in sub-urban populations in the Mozambique study [26]. This shift has been demonstrated to be associated with inadequate sanitation, poor hygiene, rise in rodent population and poor disposal of solid waste. With the rising trend of rural-urban/sub-urban migration, coupled with attendant problems such as frequent floods and global warming, it can be predicted that leptospirosis will pose a great public health threat in the near future. This prediction is particularly relevant for Mozambique as the country has been rated as the third most vulnerable country to extreme climate events in Africa [26].

MAT as a technique may help provide hints of animal reservoirs by showing the common serogroups prevalent in a specific locality, although the technique is not serovar-specific [96]. In a study by Samir et al. (2015), there was a disagreement between PCR and MAT results in evaluating seroprevalence in humans. This highlights the need for increased surveillance and well-planned 
prevention and control programs, particularly those that target animals as the source of infection to eradicate the disease. Vaccination programs targeted at livestock and pets would help reduce the disease burden in animals, and reduce environmental contamination and exposure of humans to the pathogen. The detection of Leptospira interrogans in banded mongoose (Mungos mungo) in Botswana is an important finding, as they are also found frequently in central and eastern Africa, and are thus important to public health [45]. Situations that force humans, domestic animals and wildlife animals to share sources of water put populations at risk of outbreaks, while flooding rivers may carry soil contaminated with urine [45].

\subsection{Bovine Tuberculosis}

In cattle, post-mortem and bacteriological examinations of suspected lesions are important ways of confirming the presence of bovine tuberculosis. The mycobacterial species concerned are characterised by molecular methods, while the specificity of diagnosis may be improved by histopathological examination. As accurate diagnosis is key, routine culturing and other reliable diagnostic techniques are required to make definitive diagnosis, to help fashion control programs [55]. Phenotype-based characterisation of mycobacteria is laborious and less reproducible compared to molecular detection techniques, such as PCR, which has a higher sensitivity and specificity, and is faster and more reliable [55]. However, conventional detection methods remain useful in many developing countries, as molecular techniques may not be readily available due to cost. It was found that PCR showed high sensitivity and specificity, and thus can be relied upon to confirm the results of tests from Ziehl-Neelsen (ZN) staining, tuberculin skin test and postmortem, particularly as these tests are liable to give false positives [56].

\subsection{Rickettsiosis}

Ticks and mosquitoes are known to be the two main vectors of several human and animal pathogens [97], with recent studies indicating an increase in the number of tick-borne pathogens of humans and animals [59]. The occurrence of spotted fever group (SFG) rickettsiae differs according to the location and tick gender. The pathogen Rickettsia felis, commonly borne by fleas, causes flea-borne spotted fever, which can manifest as a mild to moderate disease, symptoms of which include cutaneous rash, fever, neurologic and digestive signs. Socolovschi et al. (2010) investigated the cause of reported febrile conditions that had tested negative for malaria [61]. The prevalence of spotted fever in all samples was $4.4 \%$, with $R$. felis infection possibly being responsible for many cases of uneruptive fevers of unknown origins particularly those accompanied with digestive, neurologic and respiratory signs [61]. Vector-borne bacterial zoonoses have complex epidemiology and ecology, meaning factors such as weather and climate can affect transmission cycles, making them hard to control [98].

\subsection{Anaplasmosis}

Ruminants and rodent species are known natural hosts for Anaplasma phagocytophilum, with humans and dogs being considered accidental hosts. However, A. platys naturally infects dogs, and is thought to be transmitted by the Rhipicephalus sanguineus group of ticks [99]. The close bond shared between humans and dogs can facilitate the transmission of pathogens between them, as dogs spend time outdoors and also closely associated with humans, which means that they are a good source of tick-borne infections [64]. The first study to highlight the prevalence of Anaplasma spp. in dogs in Zambia [64] is important from the viewpoint of 'One Health', as it recognises dogs as important reservoirs of zoonotic pathogens, thus increasing the risk for human infection. Increased sensitisation among veterinarians and dog owners is essential. Other measures such as use of insect repellents, insecticide treatment of pets and frequent tick checks on pets after outdoor activity in high risk communities will help check the spread of vector-borne pathogens [98]. 


\subsection{Lyme Borreliosis}

Lyme borreliosis is mainly transmitted through Ixodes ticks to mammalian hosts. The main reservoirs for the disease are deer and small rodents especially mice. Elhelw et al. (2014) in their study of Lyme borreliosis in Egypt found the OspA gene (outer surface protein A gene) and anti-B. burgdorferi IgM by PCR and ELISA, respectively, whereas culture identification techniques showed a low sensitivity for the recovery of Borrelia burgdorferi isolates in humans [69]. Thus, it would be more tenable to rely on PCR and ELISA when dealing with this pathogen. The prior exposure of human contacts to tick bite in that study, suggests a possible zoonotic transfer.

\subsection{Bartonellosis, Plague, Tularaemia and Anthrax}

Bartonella species are mostly thought to be transmitted by arthropod vectors. The detection of bacterial DNA, however, does not necessarily indicate that the organism is viable or that the vector is capable of transmitting the pathogen [68].

Plague occurs worldwide, although most suspected human cases are reported in developing countries, with sub-Saharan Africa accounting for more than 95\% of the human cases worldwide [29]. In light of the fact that rodents and fleas are natural reservoirs of Yersinia pestis-the causative pathogen for plague [29] — Forrester and colleagues found a correlation between reports of human plague and a large number of dead rats in a village, which is unsurprising considering that close contact with infected rodents is a risk factor for the disease. Even though plague is a less frequent zoonosis, it still retains public health significance because of its epidemic potential [98].

As was observed in other studies, most febrile cases that tested positive to tularaemia in a Kenya study [30] were not recognised by clinicians and hence the appropriate treatment protocol was not followed. Indeed, most cases were treated with antimalarials and/or beta-lactam antibiotics which are ineffective against the pathogen of concern.

In developing countries, where there is high level of interaction at the human-animal interface, anthrax, caused by Bacillus anthracis, continues to pose public health threats [71]. Testing the susceptibility of bacterial isolates to some antibiotics, Hang'ombe et al. (2012) in an investigation of a suspected anthrax outbreak, observed that all tested isolates were sensitive to the antibiotics used (including ciprofloxacin and doxycycline), except vancomycin. Ciprofloxacin and doxycycline are recommended by the US Centers for Disease Control and Prevention (CDC) as first line treatment for anthrax [100].

\subsection{Other Zoonotic Pathogens}

Other bacterial zoonotic pathogens, including Salmonella spp. and Campylobacter spp., which can be transmitted between livestock and humans, were reported by various studies.

Salmonellosis is one of the most common foodborne zoonoses in developing and industrialised countries [72]. The presence of Salmonella in food animals and animal products presents a food safety threat [72]. Food safety measures need to be intensified particularly as multidrug resistant pathogenic strains are increasing.

Campylobacter frequently colonizes different species of animals asymptomatically, but produces acute and self-limiting intestinal infections in humans [76], with undercooked and raw poultry meat having been particularly found to be culpable. In a study by Komba et al. (2015), Campylobacter isolates showed $84.3 \%$ resistance to erythromycin, which is worrying, considering that erythromycin together with ciprofloxacin are the antibiotics of choice in the treatment of severe, nonself-limiting Campylobacter infections such as septic arthritis, bacteremia and prolonged enteritis [76,101]. Salmonellosis and campylobacteriosis are reported as the commonest foodborne bacterial zoonoses in Europe with eggs and mixed foods as the most culpable food sources [98]. However, prevalence data for these two zoonoses are lacking in Africa. The overuse of antibiotics (mainly as growth promoters) in animal husbandry, coupled with the close contact of humans and farm animals, facilitates the emergence 
of resistant zoonotic bacterial pathogens. Indeed, studies elsewhere have shown that resistance in pathogenic zoonotic bacteria and/or changes in faecal microbiota increases shortly after the introduction of antibiotics in veterinary practice [102-104]. Stricter controls concerning the nontherapeutic use of antibiotics in animal husbandry are required.

\subsection{Limitations of the Data}

The lack of surveys on zoonoses at the national levels, as well as individual studies not being representative enough, might affect the true estimates of zoonoses in individual countries and across the continent. Furthermore, individual reports included in this study have not factored in confounding bias, which may affect the true estimates.

\section{Conclusions}

Bacterial zoonotic diseases pose a significant burden in Africa, although the actual socioeconomic burden is unknown. Interactions at the human-livestock and human-wildlife interfaces contribute to the transmission of zoonoses, with a wide range of hosts and vectors playing roles. Bacterial zoonoses have a dual impact on both livestock production systems and human health. The lack of diagnostic tests and clinical awareness for many zoonotic diseases in most parts of Africa is worrying, being reflected in the low levels of diagnoses on the continent in clinical settings. A 'One Health' approach, which involves the concerted efforts of veterinarians, physicians, public health workers and epidemiologists, is essential in the policy schemes that are aimed at controlling and preventing the transmission of such diseases.

Author Contributions: Conceptualization, M.E.E.Z.; methodology, J.A. and M.E.E.Z.; validation, J.A., A.N. and M.E.E.Z.; formal analysis, J.A. and M.E.Z; investigation, J.A. and M.E.E.Z.; resources, M.E.E.Z. and A.N.; data curation, J.A. and M.E.E.Z.; writing —original draft preparation, J.A. and M.E.E.Z.; writing—review and editing, M.E.E.Z., J.A. and A.N.; visualization, J.A. and M.E.E.Z.; supervision, M.E.E.Z.; project administration, M.E.E.Z.

Funding: This research received no external funding.

Acknowledgments: The authors would like to thank the two anonymous reviewers for their comments that improved the manuscript. Authors would like to thank Zelalem G. Dessie from the School of Mathematics, Statistics and Computer Science for his assistance.

Conflicts of Interest: The authors declare no conflict of interest.

\section{References}

1. Simpson, G.J.; Quan, V.; Frean, J.; Knobel, D.L.; Rossouw, J.; Weyer, J.; Marcotty, T.; Godfroid, J.; Blumberg, L.H. Prevalence of selected zoonotic diseases and risk factors at a human-wildlife-livestock interface in Mpumalanga Province, South Africa. Vector-Borne Zoonotic Dis. 2018, 18, 303-310. [CrossRef]

2. Jones, K.E.; Patel, N.G.; Levy, M.A.; Storeygard, A.; Balk, D.; Gittleman, J.L.; Daszak, P. Global trends in emerging infectious diseases. Nature 2008, 451, 990-993. [CrossRef] [PubMed]

3. Grace, D.; Gilbert, J.; Randolph, T.; Kang'ethe, E. The multiple burdens of zoonotic disease and an ecohealth approach to their assessment. Trop. Anim. Health Prod. 2012, 44, 67-73. [CrossRef]

4. Grace, D.; Mutua, F.; Ochungo, P.; Kruska, R.; Jones, K.; Brierley, L.; Lapar, M.; Said, M.; Herrero, M.; Phuc, P. Mapping of Poverty and Likely Zoonoses Hotspots; ILRI: Nairobi, Kenya, 2012.

5. Grace, D.; Lindahl, J.; Wanyoike, F.; Bett, B.; Randolph, T.; Rich, K.M. Poor livestock keepers: Ecosystem-poverty-health interactions. Phil. Trans. R. Soc. B 2017, 372, 20160166. [CrossRef]

6. WHO. Who Estimates of the Global Burden of Foodborne Diseases: Foodborne Disease Burden Epidemiology Reference Group 2007-2015; WHO: Geneva, Switzerland, 2015.

7. Fèvre, E.M.; Glanville, W.A.; Thomas, L.F.; Cook, E.A.; Kariuki, S.; Wamae, C.N. An integrated study of human and animal infectious disease in the Lake Victoria crescent small-holder crop-livestock production system, Kenya. BMC Infect. Dis. 2017, 17, 457. [CrossRef] [PubMed] 
8. Munyua, P.; Bitek, A.; Osoro, E.; Pieracci, E.G.; Muema, J.; Mwatondo, A.; Kungu, M.; Nanyingi, M.; Gharpure, R.; Njenga, K. Prioritization of zoonotic diseases in Kenya, 2015. PLoS ONE 2016, 11, e0161576. [CrossRef]

9. Centers for Disease Control and Prevention. Bioterrorism Agents/Diseases. Emergency Preparedness and Response. Centers for Disease Control and Prevention: Atlanta, GA, USA. Available online: https://emergency.cdc.gov/agent/agentlist-category.asp (accessed on 9 April 2018).

10. Rodríguez-Prieto, V.; Vicente-Rubiano, M.; Sánchez-Matamoros, A.; Rubio-Guerri, C.; Melero, M.; Martínez-López, B.; Martínez-Avilés, M.; Hoinville, L.; Vergne, T.; Comin, A. Systematic review of surveillance systems and methods for early detection of exotic, new and re-emerging diseases in animal populations. Epidemiol. Infect. 2015, 143, 2018-2042. [CrossRef]

11. Zumla, A.; Dar, O.; Kock, R.; Muturi, M.; Ntoumi, F.; Kaleebu, P.; Eusebio, M.; Mfinanga, S.; Bates, M.; Mwaba, P. Taking Forward a 'One Health'approach for Turning the Tide Against the Middle East Respiratory Syndrome Coronavirus and Other Zoonotic Pathogens with Epidemic Potential; Elsevier: Amsterdam, The Netherlands, 2016.

12. Dweba, C.C.; Zishiri, O.T.; El Zowalaty, M.E. Methicillin-resistant Staphylococcus aureus: Livestock-associated, antimicrobial, and heavy metal resistance. Infect. Drug Resist. 2018, 11, 2479.

13. Holmes, A.H.; Moore, L.S.; Sundsfjord, A.; Steinbakk, M.; Regmi, S.; Karkey, A.; Guerin, P.J.; Piddock, L.J. Understanding the mechanisms and drivers of antimicrobial resistance. Lancet 2016, 387, 176-187. [CrossRef]

14. Laxminarayan, R.; Duse, A.; Wattal, C.; Zaidi, A.K.; Wertheim, H.F.; Sumpradit, N.; Vlieghe, E.; Hara, G.L.; Gould, I.M.; Goossens, H. Antibiotic resistance-The need for global solutions. Lancet Infect. Dis. 2013, 13, 1057-1098. [CrossRef]

15. Vanderburg, S.; Rubach, M.P.; Halliday, J.E.; Cleaveland, S.; Reddy, E.A.; Crump, J.A. Epidemiology of Coxiella burnetii infection in Africa: A one health systematic review. PLoS Negl. Trop. Dis. 2014, 8, e2787. [CrossRef]

16. Cleaveland, S.; Sharp, J.; Abela-Ridder, B.; Allan, K.J.; Buza, J.; Crump, J.A.; Davis, A.; Del Rio Vilas, V.J.; de Glanville, W.A.; Kazwala, R.R.; et al. One Health contributions towards more effective and equitable approaches to health in low-and middle-income countries. Philos. Trans. R. Soc. B: Biol. Sci. 2017, 372, 20160168.

17. United Nations Statistics Division. Composition of Macro Geographical (Continental) Regions, Geographical Sub-Regions, and Selected Economic and Other Groupings; United Nations Statistics Division: New York, NY, USA, 2010.

18. IBM Corp. Released 2017. IBM SPSS Statistics for Windows, Version 25.0; IBM Corp: Armonk, NY, USA, 2017.

19. R Development Core Team. R: A Language and Environment for Statistical Computing; R Foundation for Statistical Computing: Vienna, Austria, 2008; ISBN 3-900051-07-0.

20. Njeru, J.; Melzer, F.; Wareth, G.; El-Adawy, H.; Henning, K.; Pletz, M.W.; Heller, R.; Kariuki, S.; Fèvre, E.; Neubauer, H. Human brucellosis in febrile patients seeking treatment at remote hospitals, Northeastern Kenya, 2014-2015. Emerg. Infect. Dis. 2016, 22, 2160-2164. [CrossRef]

21. Bouley, A.J.; Biggs, H.M.; Stoddard, R.A.; Morrissey, A.B.; Bartlett, J.A.; Afwamba, I.A.; Maro, V.P.; Kinabo, G.D.; Saganda, W.; Cleaveland, S. Brucellosis among hospitalized febrile patients in Northern Tanzania. Am. J. Trop. Med. Hyg. 2012, 87, 1105-1111. [CrossRef]

22. Chipwaza, B.; Mhamphi, G.G.; Ngatunga, S.D.; Selemani, M.; Amuri, M.; Mugasa, J.P.; Gwakisa, P.S. Prevalence of bacterial febrile illnesses in children in Kilosa District, Tanzania. PLoS Negl. Trop. Dis. 2015, 9, e0003750. [CrossRef]

23. Njeru, J.; Henning, K.; Pletz, M.; Heller, R.; Forstner, C.; Kariuki, S.; Fèvre, E.; Neubauer, H. Febrile patients admitted to remote hospitals in northeastern Kenya: Seroprevalence, risk factors and a clinical prediction tool for Q-fever. BMC Infect. Dis. 2016, 16, 244. [CrossRef]

24. Angelakis, E.; Mediannikov, O.; Socolovschi, C.; Mouffok, N.; Bassene, H.; Tall, A.; Niangaly, H.; Doumbo, O.; Znazen, A.; Sarih, M. Coxiella burnetii-positive PCR in febrile patients in rural and urban Africa. Int. J. Infect. Dis. 2014, 28, 107-110. [CrossRef]

25. Prabhu, M.; Nicholson, W.L.; Roche, A.J.; Kersh, G.J.; Fitzpatrick, K.A.; Oliver, L.D.; Massung, R.F.; Morrissey, A.B.; Bartlett, J.A.; Onyango, J.J. Q fever, spotted fever group, and typhus group rickettsioses among hospitalized febrile patients in northern Tanzania. Clin. Infect. Dis. 2011, 53, e8-e15. [CrossRef] 
26. Ribeiro, P.; Bhatt, N.; Ali, S.; Monteiro, V.; da Silva, E.; Balassiano, I.T.; Aquino, C.; de Deus, N.; Guiliche, O.; Muianga, A.F. Seroepidemiology of leptospirosis among febrile patients in a rapidly growing sub-urban slum and a flood-vulnerable rural district in Mozambique, 2012-2014: Implications for the management of fever. Int. J. Infect. Dis. 2017, 64, 50-57. [CrossRef]

27. Biggs, H.M.; Bui, D.M.; Galloway, R.L.; Stoddard, R.A.; Shadomy, S.V.; Morrissey, A.B.; Bartlett, J.A.; Onyango, J.J.; Maro, V.P.; Kinabo, G.D. Leptospirosis among hospitalized febrile patients in Northern Tanzania. Am. J. Trop. Med. Hyg. 2011, 85, 275-281. [CrossRef]

28. Samir, A.; Soliman, R.; El-Hariri, M.; Abdel-Moein, K.; Hatem, M.E. Leptospirosis in animals and human contacts in Egypt: Broad range surveillance. Rev. Soc. Bras. Med. Trop. 2015, 48, 272-277. [CrossRef]

29. Forrester, J.D.; Apangu, T.; Griffith, K.; Acayo, S.; Yockey, B.; Kaggwa, J.; Kugeler, K.J.; Schriefer, M.; Sexton, C.; Beard, C.B. Patterns of human plague in Uganda, 2008-2016. Emerg. Infect. Dis. 2017, 23, 1517-1521. [CrossRef]

30. Njeru, J.; Tomaso, H.; Mertens, K.; Henning, K.; Wareth, G.; Heller, R.; Kariuki, S.; Fèvre, E.M.; Neubauer, H.; Pletz, M. Serological evidence of Francisella tularensis in febrile patients seeking treatment at remote hospitals, northeastern Kenya, 2014-2015. New Microbes New Infect. 2017, 19, 62-66. [CrossRef]

31. Wareth, G.; Melzer, F.; Böttcher, D.; El-Diasty, M.; El-Beskawy, M.; Rasheed, N.; Schmoock, G.; Roesler, U.; Sprague, L.D.; Neubauer, H. Molecular typing of isolates obtained from aborted foetuses in Brucella-free Holstein dairy cattle herd after immunisation with Brucella abortus RB51 vaccine in Egypt. Acta Trop. 2016, 164, 267-271. [CrossRef]

32. Megersa, B.; Biffa, D.; Niguse, F.; Rufael, T.; Asmare, K.; Skjerve, E. Cattle brucellosis in traditional livestock husbandry practice in southern and eastern Ethiopia, and its zoonotic implication. Acta Vet. Scand. 2011, 53, 24. [CrossRef]

33. Wareth, G.; Melzer, F.; Elschner, M.C.; Neubauer, H.; Roesler, U. Detection of Brucella melitensis in bovine milk and milk products from apparently healthy animals in Egypt by real-time PCR. J. Infect. Dev. Ctries 2014, 8, 1339-1343. [CrossRef]

34. Erume, J.; Roesel, K.; Dione, M.M.; Ejobi, F.; Mboowa, G.; Kungu, J.M.; Akol, J.; Pezo, D.; El-Adawy, H.; Melzer, F. Serological and molecular investigation for brucellosis in swine in selected districts of Uganda. Trop. Anim. Health Prod. 2016, 48, 1147-1155. [CrossRef]

35. Wareth, G.; Melzer, F.; Tomaso, H.; Roesler, U.; Neubauer, H. Detection of Brucella abortus DNA in aborted goats and sheep in Egypt by real-time PCR. BMC Res. Notes 2015, 8, 212. [CrossRef]

36. Nasinyama, G.; Ssekawojwa, E.; Opuda, J.; Grimaud, P.; Etter, E.; Bellinguez, A. Brucella sero-prevalence and modifiable risk factors among predisposed cattle keepers and consumers of un-pasteurized milk in Mbarara and Kampala Districts, Uganda. Afr. Health Sci. 2014, 14, 790-796. [CrossRef]

37. Sylla, S.; Sidimé, Y.; Sun, Y.; Doumbouya, S.; Cong, Y. Seroprevalence investigation of bovine brucellosis in Macenta and Yomou, Guinea. Trop. Anim. Health Prod. 2014, 46, 1185-1191. [CrossRef]

38. Osoro, E.M.; Munyua, P.; Omulo, S.; Ogola, E.; Ade, F.; Mbatha, P.; Mbabu, M.; Kairu, S.; Maritim, M.; Thumbi, S.M. Strong association between human and animal Brucella seropositivity in a linked study in Kenya, 2012-2013. Am. J. Trop. Med. Hyg. 2015, 93, 224-231. [CrossRef]

39. Kanouté, Y.B.; Gragnon, B.G.; Schindler, C.; Bonfoh, B.; Schelling, E. Epidemiology of brucellosis, Q fever and Rift Valley fever at the human and livestock interface in northern Côte d'Ivoire. Acta Trop. 2017, 165, 66-75. [CrossRef]

40. Boone, I.; Henning, K.; Hilbert, A.; Neubauer, H.; Von Kalckreuth, V.; Dekker, D.M.; Schwarz, N.G.; Pak, G.D.; Krüger, A.; Hagen, R.M. Are brucellosis, Q fever and melioidosis potential causes of febrile illness in Madagascar? Acta Trop. 2017, 172, 255-262. [CrossRef]

41. Dean, A.S.; Bonfoh, B.; Kulo, A.E.; Boukaya, G.A.; Amidou, M.; Hattendorf, J.; Pilo, P.; Schelling, E. Epidemiology of brucellosis and $\mathrm{Q}$ fever in linked human and animal populations in northern Togo. PLoS ONE 2013, 8, e71501. [CrossRef]

42. Tebug, S.; Njunga, G.R.; Chagunda, M.G.; Mapemba, J.P.; Awah-Ndukum, J.; Wiedemann, S. Risk, knowledge and preventive measures of smallholder dairy farmers in northern Malawi with regard to zoonotic brucellosis and bovine tuberculosis. Onderstepoort J. Vet. Res. 2014, 81, 1-6. [CrossRef]

43. Lagadec, E.; Gomard, Y.; Guernier, V.; Dietrich, M.; Pascalis, H.; Temmam, S.; Ramasindrazana, B.; Goodman, S.M.; Tortosa, P.; Dellagi, K. Pathogenic Leptospira spp. in bats, Madagascar and Union of the Comoros. Emerg. Infect. Dis. 2012, 18, 1696-1698. [CrossRef] 
44. Dietrich, M.; Wilkinson, D.A.; Soarimalala, V.; Goodman, S.M.; Dellagi, K.; Tortosa, P. Diversification of an emerging pathogen in a biodiversity hotspot: L. eptospira in endemic small mammals of Madagascar. Mol. Ecol. 2014, 23, 2783-2796. [CrossRef]

45. Jobbins, S.; Sanderson, C.; Alexander, K. Leptospira interrogans at the human-wildlife interface in northern Botswana: A newly identified public health threat. Zoonoses Public Health 2014, 61, 113-123. [CrossRef]

46. Dobigny, G.; Garba, M.; Tatard, C.; Loiseau, A.; Galan, M.; Kadaouré, I.; Rossi, J.-P.; Picardeau, M.; Bertherat, E. Urban market gardening and rodent-borne pathogenic Leptospira in arid zones: A case study in Niamey, Niger. PLoS Negl. Trop. Dis. 2015, 9, e0004097. [CrossRef]

47. Allan, K.J.; Halliday, J.E.; Moseley, M.; Carter, R.W.; Ahmed, A.; Goris, M.G.; Hartskeerl, R.A.; Keyyu, J.; Kibona, T.; Maro, V.P. Assessment of animal hosts of pathogenic Leptospira in northern Tanzania. PLoS Negl. Trop. Dis. 2018, 12, e0006444. [CrossRef]

48. Abdel-Moein, K.A.; Hamza, D.A. The burden of Coxiella burnetii among aborted dairy animals in Egypt and its public health implications. Acta Trop. 2017, 166, 92-95. [CrossRef]

49. Khaled, H.; Sidi-Boumedine, K.; Merdja, S.; Dufour, P.; Dahmani, A.; Thiéry, R.; Rousset, E.; Bouyoucef, A. Serological and molecular evidence of $\mathrm{Q}$ fever among small ruminant flocks in Algeria. Comp. Immunol. Microbiol. Infect. Dis. 2016, 47, 19-25. [CrossRef]

50. Abushahba, M.F.; Abdelbaset, A.E.; Rawy, M.S.; Ahmed, S.O. Cross-sectional study for determining the prevalence of $Q$ fever in small ruminants and humans at El Minya Governorate, Egypt. BMC Res. Notes 2017, 10, 538. [CrossRef] [PubMed]

51. Bok, J.; Hogerwerf, L.; Germeraad, E.A.; Roest, H.I.; Faye-Joof, T.; Jeng, M.; Nwakanma, D.; Secka, A.; Stegeman, A.; Goossens, B. Coxiella burnetii ( $Q$ fever) prevalence in associated populations of humans and small ruminants in the Gambia. Trop. Med. Int. Health 2017, 22, 323-331. [CrossRef] [PubMed]

52. Wardrop, N.A.; Thomas, L.F.; Cook, E.A.; de Glanville, W.A.; Atkinson, P.M.; Wamae, C.N.; Fèvre, E.M. The sero-epidemiology of Coxiella burnetii in humans and cattle, western Kenya: Evidence from a cross-sectional study. Plos Negl. Trop. Dis. 2016, 10, e0005032. [CrossRef]

53. Mtshali, K.; Nakao, R.; Sugimoto, C.; Thekisoe, O. Occurrence of Coxiella burnetii, Ehrlichia canis, Rickettsia species and Anaplasma phagocytophilum-like bacterium in ticks collected from dogs and cats in South Africa. J. S. Afr. Vet. Assoc. 2017, 88, 1-6. [CrossRef] [PubMed]

54. Kamani, J.; Baneth, G.; Gutiérrez, R.; Nachum-Biala, Y.; Mumcuoglu, K.Y.; Harrus, S. Coxiella burnetii and Rickettsia conorii: Two zoonotic pathogens in peridomestic rodents and their ectoparasites in Nigeria. Ticks Tick-Borne Dis. 2018, 9, 86-92. [CrossRef] [PubMed]

55. El Tigani, A.; El Sanousi, S.M.; Gameel, A.; El Beir, H.; Fathelrahman, M.; Terab, N.M.; Muaz, M.A.; Hamid, M.E. Bovine tuberculosis in South Darfur State, Sudan: An abattoir study based on microscopy and molecular detection methods. Trop. Anim. Health Prod. 2013, 45, 469-472.

56. Sa'idu, A.; Okolocha, E.; Dzikwi, A.; Kwaga, J.; Gamawa, A.; Usman, A.; Maigari, S.; Ibrahim, S. Detection of Mycobacterium bovis in organs of slaughtered cattle by DNA-based polymerase chain reaction and Ziehl-Neelsen techniques in Bauchi State, Nigeria. J. Vet. Med. 2015, 2015. [CrossRef]

57. Okeke, L.A.; Fawole, O.; Muhammad, M.; Okeke, I.O.; Nguku, P.; Wasswa, P.; Dairo, D.; Cadmus, S. Bovine tuberculosis: A retrospective study at Jos abattoir, Plateau State, Nigeria. Pan Afr. Med J. 2016, 25. [CrossRef]

58. Okeke, L.A.; Cadmus, S.; Okeke, I.O.; Muhammad, M.; Awoloh, O.; Dairo, D.; Waziri, E.N.; Olayinka, A.; $\mathrm{Nguku}$, P.M.; Fawole, O. Prevalence and risk factors of Mycobacterium tuberculosis complex infection in slaughtered cattle at Jos South abattoir, Plateau State, Nigeria. Pan Afr. Med. J. 2014, 18. [CrossRef]

59. Kumsa, B.; Socolovschi, C.; Raoult, D.; Parola, P. Spotted fever group Rickettsiae in Ixodid ticks in Oromia, Ethiopia. Ticks Tick-Borne Dis. 2015, 6, 8-15. [CrossRef]

60. Moumouni, P.F.A.; Terkawi, M.A.; Jirapattharasate, C.; Cao, S.; Liu, M.; Nakao, R.; Umemiya-Shirafuji, R.; Yokoyama, N.; Sugimoto, C.; Fujisaki, K. Molecular detection of spotted fever group rickettsiae in Amblyomma variegatum ticks from Benin. Ticks Tick-Borne Dis. 2016, 7, 828-833. [CrossRef] [PubMed]

61. Socolovschi, C.; Mediannikov, O.; Sokhna, C.; Tall, A.; Diatta, G.; Bassene, H.; Trape, J.-F.; Raoult, D. Rickettsia felis-Associated uneruptive fever, Senegal. Emerg. Infect. Dis. 2010, 16, 1140. [CrossRef] [PubMed]

62. Mwamuye, M.M.; Kariuki, E.; Omondi, D.; Kabii, J.; Odongo, D.; Masiga, D.; Villinger, J. Novel rickettsia and emergent tick-borne pathogens: A molecular survey of ticks and tick-borne pathogens in Shimba Hills National Reserve, Kenya. Ticks Tick-Borne Dis. 2017, 8, 208-218. [CrossRef] [PubMed] 
63. Nakayima, J.; Hayashida, K.; Nakao, R.; Ishii, A.; Ogawa, H.; Nakamura, I.; Moonga, L.; Hang'ombe, B.M.; Mweene, A.S.; Thomas, Y. Detection and characterization of zoonotic pathogens of free-ranging non-human primates from Zambia. Parasites Vectors 2014, 7, 490. [CrossRef] [PubMed]

64. Vlahakis, P.A.; Chitanga, S.; Simuunza, M.C.; Simulundu, E.; Qiu, Y.; Changula, K.; Chambaro, H.M.; Kajihara, M.; Nakao, R.; Takada, A. Molecular detection and characterization of zoonotic Anaplasma species in domestic dogs in Lusaka, Zambia. Ticks Tick-Borne Dis. 2018, 9, 39-43. [CrossRef]

65. Said, M.B.; Belkahia, H.; El Mabrouk, N.; Saidani, M.; Alberti, A.; Zobba, R.; Cherif, A.; Mahjoub, T.; Bouattour, A.; Messadi, L. Anaplasma platys-like strains in ruminants from Tunisia. Infect. Genet. Evol. 2017, 49, 226-233. [CrossRef]

66. Kelly, P.; Marabini, L.; Dutlow, K.; Zhang, J.; Loftis, A.; Wang, C. Molecular detection of tick-borne pathogens in captive wild felids, Zimbabwe. Parasites Vectors 2014, 7, 514. [CrossRef]

67. Kamani, J.; Baneth, G.; Mitchell, M.; Mumcuoglu, K.Y.; Gutiérrez, R.; Harrus, S. Bartonella species in bats (Chiroptera) and bat flies (Nycteribiidae) from Nigeria, West Africa. Vector-Borne Zoonotic Dis. 2014, 14, 625-632. [CrossRef]

68. Billeter, S.; Hayman, D.; Peel, A.; Baker, K.; Wood, J.; Cunningham, A.; Suu-Ire, R.; Dittmar, K.; Kosoy, M. Bartonella species in bat flies (Diptera: Nycteribiidae) from Western Africa. Parasitology 2012, 139, 324-329. [CrossRef]

69. Elhelw, R.A.; El-Enbaawy, M.I.; Samir, A. Lyme borreliosis: A neglected zoonosis in Egypt. Acta Trop. 2014, 140, 188-192. [CrossRef]

70. Schwan, T.G.; Anderson, J.M.; Lopez, J.E.; Fischer, R.J.; Raffel, S.J.; McCoy, B.N.; Safronetz, D.; Sogoba, N.; Maïga, O.; Traoré, S.F. Endemic foci of the tick-borne relapsing fever spirochete Borrelia crocidurae in Mali, West Africa, and the potential for human infection. Plos Negl. Trop. Dis. 2012, 6, e1924. [CrossRef]

71. Hang'ombe, M.B.; Mwansa, J.C.; Muwowo, S.; Mulenga, P.; Kapina, M.; Musenga, E.; Squarre, D.; Mataa, L.; Thomas, S.Y.; Ogawa, H. Human-animal anthrax outbreak in the Luangwa Valley of Zambia in 2011. Trop. Doct. 2012, 42, 136-139. [CrossRef]

72. Ombui, J.N.; Mitema, E.S.; Kikuvi, G.M. Serotypes and antimicrobial resistance profiles of Salmonella isolates from pigs at slaughter in Kenya. J. Infect. Dev. Ctries 2010, 4, 243-248.

73. Eguale, T.; Engidawork, E.; Gebreyes, W.A.; Asrat, D.; Alemayehu, H.; Medhin, G.; Johnson, R.P.; Gunn, J.S. Fecal prevalence, serotype distribution and antimicrobial resistance of Salmonellae in dairy cattle in central Ethiopia. BMC Microbiol. 2016, 16, 20. [CrossRef]

74. Kiflu, B.; Alemayehu, H.; Abdurahaman, M.; Negash, Y.; Eguale, T. Salmonella serotypes and their antimicrobial susceptibility in apparently healthy dogs in Addis Ababa, Ethiopia. BMC Vet. Res. 2017, 13, 134. [CrossRef]

75. Ahmed, H.A.; El-Hofy, F.I.; Shafik, S.M.; Abdelrahman, M.A.; Elsaid, G.A. Characterization of virulence-associated genes, antimicrobial resistance genes, and class 1 integrons in Salmonella enterica serovar typhimurium isolates from chicken meat and humans in Egypt. Foodborne Pathog. Dis. 2016, 13, 281-288. [CrossRef]

76. Komba, E.V.; Mdegela, R.H.; Msoffe, P.; Nielsen, L.N.; Ingmer, H. Prevalence, antimicrobial resistance and risk factors for thermophilic Campylobacter infections in symptomatic and asymptomatic humans in Tanzania. Zoonoses Public Health 2015, 62, 557-568. [CrossRef]

77. De Vries, S.P.; Vurayai, M.; Holmes, M.; Gupta, S.; Bateman, M.; Goldfarb, D.; Maskell, D.J.; Matsheka, M.I.; Grant, A.J. Phylogenetic analyses and antimicrobial resistance profiles of Campylobacter spp. from diarrhoeal patients and chickens in Botswana. PLoS ONE 2018, 13, e0194481. [CrossRef]

78. Grace, D.; Mutua, F.; Ochungo, P.; Kruska, R.L.; Jones, K.; Brierley, L.; Lapar, M.; Said, M.Y.; Herrero, M.T.; Phuc, P.M.; et al. Mapping of poverty and likely zoonoses hotspots. Project 4. Report to the UK Department for International Development. International Livestock Research Institute: Nairobi, Kenya, 2012. Available online: http://cgspace.cgiar.org/handle/10568/21161 (accessed on 11 April 2019).

79. Kelly, A.; Osburn, B.; Salman, M. Veterinary medicine's increasing role in global health. Lancet Glob. Health. 2014, 2, e379-e380. [CrossRef]

80. Gebreyes, W.A.; Dupouy-Camet, J.; Newport, M.J.; Oliveira, C.J.; Schlesinger, L.S.; Saif, Y.M.; Kariuki, S.; Saif, L.J.; Saville, W.; Wittum, T.; et al. The global one health paradigm: Challenges and opportunities for tackling infectious diseases at the human, animal, and environment interface in low-resource settings. Plos Negl. Trop. Dis. 2014, 8, e3257. [CrossRef] 
81. Belay, E.D.; Kile, J.C.; Hall, A.J.; Barton-Behravesh, C.; Parsons, M.B.; Salyer, S.; Walke, H. Zoonotic disease programs for enhancing global health security. Emerg. Infect. Dis. 2017, 23, S65.

82. Cunningham, A.A.; Daszak, P.; Wood, J.L. One Health, emerging infectious diseases and wildlife: Two decades of progress? Philos. Trans. R. Soc. B: Biol. Sci. 2017, 372, 20160167. [CrossRef]

83. World Bank. People, Pathogens and Our Planet. Volume 2, The Economics of One Health. World Bank Report (\#69145-GLB); World Bank: Washington, DC, USA, 2012; Available online: http://documents.worldbank.org/ curated/en/612341468147856529/People-pathogens-and-our-planet-the-economics-of-one-health (accessed on 11 April 2019).

84. Coker, R.; Rushton, J.; Mounier-Jack, S.; Karimuribo, E.; Lutumba, P.; Kambarage, D.; Pfeiffer, D.U.; Stärk, K.; Rweyemamu, M. Towards a conceptual framework to support one-health research for policy on emerging zoonoses. Lancet Infect. Dis. 2011, 11, 326-331. [CrossRef]

85. Molyneux, D.; Hallaj, Z.; Keusch, G.T.; McManus, D.P.; Ngowi, H.; Cleaveland, S.; Ramos-Jimenez, P.; Gotuzzo, E.; Kar, K.; Sanchez, A.; et al. Zoonoses and marginalised infectious diseases of poverty: Where do we stand? Parasites Vectors 2011, 4, 106.

86. Wareth, G.; Hikal, A.; Refai, M.; Melzer, F.; Roesler, U.; Neubauer, H. Animal brucellosis in Egypt. J. Infect. Dev. Ctries 2014, 8, 1365-1373. [CrossRef]

87. Al, S.D.; Tomaso, H.; Nöckler, K.; Neubauer, H.; Frangoulidis, D. Laboratory-based diagnosis of brucellosis-A review of the literature. Part II: Serological tests for brucellosis. Clin. Lab. 2003, 49, 577-589.

88. Ari, M.D.; Guracha, A.; Fadeel, M.A.; Njuguna, C.; Njenga, M.K.; Kalani, R.; Abdi, H.; Warfu, O.; Omballa, V.; Tetteh, C. Challenges of establishing the correct diagnosis of outbreaks of acute febrile illnesses in Africa: The case of a likely Brucella outbreak among nomadic pastoralists, Northeast Kenya, March-July 2005. Am. J. Trop. Med. Hyg. 2011, 85, 909-912. [CrossRef]

89. Reddy, E.A.; Shaw, A.V.; Crump, J.A. Community-acquired bloodstream infections in Africa: A systematic review and meta-analysis. Lancet Infect. Dis. 2010, 10, 417-432. [CrossRef]

90. John, K.; Fitzpatrick, J.; French, N.; Kazwala, R.; Kambarage, D.; Mfinanga, G.S.; MacMillan, A.; Cleaveland, S. Quantifying risk factors for human brucellosis in rural northern Tanzania. PLoS ONE 2010, 5, e9968. [CrossRef]

91. Swai, E.S.; Schoonman, L. Human brucellosis: Seroprevalence and risk factors related to high risk occupational groups in Tanga Municipality, Tanzania. Zoonoses Public Health 2009, 56, 183-187. [CrossRef] [PubMed]

92. Siadat, S.D.; Salmani, A.S.; Aghasadeghi, M.R. Brucellosis vaccines: An overview. In Zoonosis; Intech: Rijeka, Croatia, 2012.

93. Berhe, G.; Belihu, K.; Asfaw, Y. Seroepidemiological investigation of bovine brucellosis in the extensive cattle production system of Tigray region of Ethiopia. Int. J. Appl. Res. Vet. Med. 2007, 5, 65.

94. Onchiri, F.M.; Pavlinac, P.B.; Singa, B.O.; Naulikha, J.M.; Odundo, E.A.; Farquhar, C.; Richardson, B.A.; John-Stewart, G.; Walson, J.L. Frequency and correlates of malaria over-treatment in areas of differing malaria transmission: A cross-sectional study in rural western Kenya. Malar. J. 2015, 14, 97. [CrossRef] [PubMed]

95. Raoult, D. Chronic Q fever: Expert opinion versus literature analysis and consensus. J. Infect. 2012, 65, 102-108. [CrossRef]

96. Smythe, L.D.; Wuthiekanun, V.; Chierakul, W.; Suputtamongkol, Y.; Tiengrim, S.; Dohnt, M.F.; Symonds, M.L.; Slack, A.T.; Apiwattanaporn, A.; Chueasuwanchai, S. The microscopic agglutination test (MAT) is an unreliable predictor of infecting Leptospira serovar in Thailand. Am. J. Trop. Med. Hyg. 2009, 81, 695-697. [CrossRef]

97. Mensah, E.; El Zowalaty, M.E. Arboviruses in South Africa, known and unknown. Future Virol. 2018, 13, 787-802. [CrossRef]

98. Cantas, L.; Suer, K. The important bacterial zoonoses in "one health" concept. Front. Public Health 2014, 2, 144. [CrossRef]

99. Nicholson, W.L.; Allen, K.E.; McQuiston, J.H.; Breitschwerdt, E.B.; Little, S.E. The increasing recognition of rickettsial pathogens in dogs and people. Trends Parasitol. 2010, 26, 205-212. [CrossRef] [PubMed]

100. Centers for Disease Control and Prevention. Update: Investigation of bioterrorism-related anthrax and interim guidelines for exposure management and antimicrobial therapy, October 2001. Morb. Mortal. Wkly. Rep. 2001, 50, 909. 
101. Ghosh, R.; Uppal, B.; Aggarwal, P.; Chakravarti, A.; Jha, A.K. Increasing antimicrobial resistance of Campylobacter jejuni isolated from paediatric diarrhea cases in a tertiary care hospital of New Delhi, India. J. Clin. Diagn. Res. JCDR 2013, 7, 247. [CrossRef] [PubMed]

102. Anthony, F.; Acar, J.; Franklin, A.; Gupta, R.; Nicholls, T.; Tamura, Y.; Thompson, S.; Threlfall, E.; Vose, D.; Van Vuuren, M. Antimicrobial resistance: Responsible and prudent use of antimicrobial agents in veterinary medicine. Rev. Sci. Et Tech.-Off. Int. Des Epizoot. 2001, 20, 829-837. [CrossRef]

103. Cabello, F.C. Heavy use of prophylactic antibiotics in aquaculture: A growing problem for human and animal health and for the environment. Environ. Microbiol. 2006, 8, 1137-1144. [CrossRef] [PubMed]

104. Casewell, M.; Friis, C.; Marco, E.; McMullin, P.; Phillips, I. The European ban on growth-promoting antibiotics and emerging consequences for human and animal health. J. Antimicrob. Chemother. 2003, 52, 159-161. [CrossRef] [PubMed]

(C) 2019 by the authors. Licensee MDPI, Basel, Switzerland. This article is an open access article distributed under the terms and conditions of the Creative Commons Attribution (CC BY) license (http://creativecommons.org/licenses/by/4.0/). 